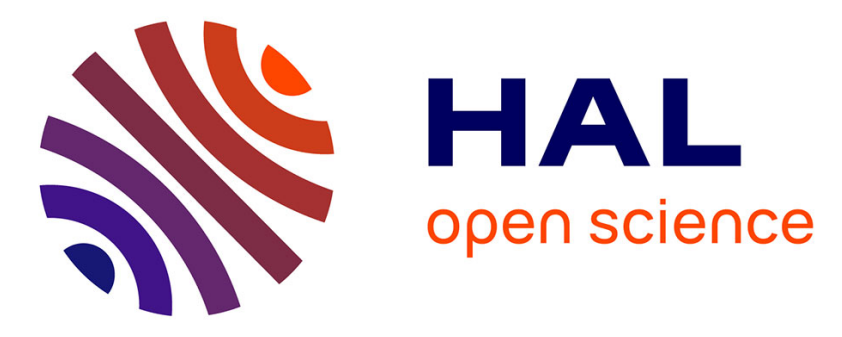

\title{
Optical and photophysical properties of anisole- and cyanobenzene-substituted perylene diimides
}

Bernard Pagoaga, Olivier Mongin, Monica Caselli, Davide Vanossi, Fabio Momicchioli, Mireille Blanchard-Desce, Gilles Lemercier, Norbert Hoffmann, Glauco Ponterini

\section{To cite this version:}

Bernard Pagoaga, Olivier Mongin, Monica Caselli, Davide Vanossi, Fabio Momicchioli, et al.. Optical and photophysical properties of anisole- and cyanobenzene-substituted perylene diimides. Physical Chemistry Chemical Physics, 2016, 18 (6), pp.4924-4941. 10.1039/c5cp07758c . hal-01269734

\section{HAL Id: hal-01269734 \\ https://hal-univ-rennes1.archives-ouvertes.fr/hal-01269734}

Submitted on 22 Mar 2016

HAL is a multi-disciplinary open access archive for the deposit and dissemination of scientific research documents, whether they are published or not. The documents may come from teaching and research institutions in France or abroad, or from public or private research centers.
L'archive ouverte pluridisciplinaire HAL, est destinée au dépôt et à la diffusion de documents scientifiques de niveau recherche, publiés ou non, émanant des établissements d'enseignement et de recherche français ou étrangers, des laboratoires publics ou privés. 


\title{
Optical and Photophysical Properties of Anisole- and Cyanobenzene- Substituted Perylene Diimides
}

\author{
Bernard Pagoaga, ${ }^{[\mathrm{a}]}$ Olivier Mongin, ${ }^{[\mathrm{b}]}$ Monica Caselli, ${ }^{[\mathrm{c}]}$ Davide Vanossi, ${ }^{[\mathrm{c}]}$ Fabio \\ Momicchioli, ${ }^{[\mathrm{c}]}$ Mireille Blanchard-Desce, ${ }^{[\mathrm{e}]}$ Gilles Lemercier, ${ }^{[\mathrm{a}]}$ Norbert Hoffmann, ${ }^{[\mathrm{a}]^{*}}$ \\ Glauco Ponterini, ${ }^{[\mathrm{d}]}{ }^{*}$ \\ ${ }^{a}$ Université de Reims Champagne-Ardenne, ICMR UMR n 7312, - BP 1039 - 51687 Reims Cedex 2, \\ France; ${ }^{b}$ Université Rennes 1, UMR CNRS 6510, Chimie et Photonique Moléculaires, Campus de \\ Beaulieu, 35042 Rennes cedex, (France); ${ }^{c}$ Dipartimento di Scienze Chimiche e Geologiche and \\ ${ }^{d}$ Dipartimento di Scienze della Vita, Università di Modena e Reggio Emilia, via Campi 183, 41125 Modena, \\ Italy.; ${ }^{e}$ Université Bordeaux, ISM, Centre National de la Recherche Scientifique, UMR 5255, F-33400 \\ Talence, France.
}

\begin{abstract}
The one- and two-photon absorption cross-sections and spectra and the photophysical properties of eight perylenetetracarboxy-3,4:9,10-diimide (PDI) derivatives are reported and analyzed. The investigated compounds are characterized by direct binding of the phenyl rings of the substituents to the bay positions of the perylene core. They have been designed to test the effects of differences in the electronic nature - electron donating (anisole) or accepting (cyanobenzene) - and binding topology (cis or trans, meta or para disubstitution or tetrasubstitution) of the bay substituents on the above optical and photophysical observables. (TD)DFT and Hückel MO calculations have provided theoretical information on the ground-state geometries, the MOs and the electronic spectra of several model compounds. For cis disubstituted and for the tetrasubstituted derivatives, strong steric interactions in the bay area determined the preferred conformations, with perylene cores distorted near the substituted bay $(s)$ and a $42-44^{\circ}$ twisting of the substituent rings relative to the core, quite irrespective of the electronic nature of the substituents. On the other hand, in transdisubstituted PDI steric hindrance in the bay areas was much weaker and similar for the cyanobenzene and the anisole derivatives. So, the large differences found in the conformational preferences were completely attributable to electronic effects. With electron-accepting cyanobenzene, the substituent rings were found normal to the central planar perylene core, thus enabling the assignment of the moderate spectroscopic effects to inductive interactions. DFT
\end{abstract}


analysis of the PDI trans-disubstituted with electron-donating anisoles gave quite strongly distorted perylene-core geometries and less twisted $\left(59^{\circ}\right)$ substituent rings. The corresponding increased substituent/core conjugative interactions resulted in new CT allowed electronic transitions and an extremely pronounced solvent-polarity dependence of the emission spectra and intensities. All anisole substituted PDI feature a very fast radiationless decay path in polar solvents, likely related with a relaxation to a charge-separated configuration in the lowest excited-state.

Keywords : Perylene-diimides; Anisole substituents; Optical properties; Two-photon absorption.

Electronic supplementary information (ESI) available. 


\section{Introduction}

Perylenetetracarboxy-3,4:9,10-diimide derivatives ${ }^{1}$ (PDI, Figure 1) are known since 1913. 1-3 Initially employed as dyes and pigments, these compounds as well as higher homologues (rylenes) have more recently shown impressive optical and electronic properties that, added to their thermal and photochemical stability, have gained them a much broader range of applications. ${ }^{4,5,6}$ The parent perylenetetracarboxy-3,4:9,10-dianhydride, compound 1 in Figure 1, is almost insoluble in all organic solvents. However, introduction of substituents at the imide nitrogens has improved solubility, whereas synthetic strategies have produced numerous 1,6,7,12(bay)-substituted derivatives characterized by a remarkable combination of optical and electronic properties. These derivatives show high extinction molar coefficients and fluorescence quantum yields and, thanks to a high carrier mobility and electron affinity, are one of the most interesting classes of n-type semiconductors. ${ }^{7}$ PDI feature an impressively wide range of technological applications. They have been used in organic electronics, ${ }^{8,9}$ as xerographic photoreceptors, ${ }^{10}$ in sensors, ${ }^{11,12}$ lasers ${ }^{13}$, optical power limiters ${ }^{14}$ and organic light emitting diodes, ${ }^{15}$ in photovoltaic cells ${ }^{16}$ and liquid crystals, ${ }^{17}$ as colorants, ${ }^{1,18}$ and as fluorescent dyes for single-molecule spectroscopy and microscopy, ${ }^{19}$ bio-imaging ${ }^{20}$ and environmental analysis. ${ }^{21}$ Again, PDI have been involved in supramolecular bioassemblies, ${ }^{22}$ for example for transmembrane structures ${ }^{23}$ or as stabilizer of DNR G-quadruplexes. ${ }^{24}$ They have been used as building blocks of light-harvesting arrays and artificial photosynthetic systems, ${ }^{25}$ and have been recently applied as photoredox catalysts in organic synthesis. ${ }^{26}$

PDI substituted at the four bay positions with electron-rich, often phenoxy- or resorcine, substituents have shown fluorescence properties that markedly depend on solvent polarity. ${ }^{27,28}$ This observation opens up yet an additional possible application for these compounds as probes of local polarity. The marked fluorescence quenching observed in polar solvents has been related with reduced conjugation between the perylene core electronic system and the orbitals of the connecting oxyaryl substituents in the lowest excited state, and has been attributed to fast radiationless decay promoted by photoinduced substituent-to-core electron transfer. ${ }^{28-31}$ Given the quasicentrosymmetrical structure of some of the disubstituted phenoxy PDI, the observation of such a marked solvent-polarity effect deserves further attention.

While the literature on the optical and fluorescence properties of PDI is copious, we believe that the effects of the nature and positions of the bay substituents on those observables still remains limited to relatively few examples, i.e., mainly aryloxy-tetrasubstituted derivatives. One- and twophoton absorption cross-sections and spectra, as well as photophysical behaviours, can be finely tuned by designing compounds with suitable electron donor or acceptor substituents, by playing 
with the substitution symmetry, or by increasing the chromophore conjugation length. With the aim of significantly broadening the landscape of substituted PDI, we describe the one- and two-photon absorption as well as the fluorescence properties of eight PDI (Figure 1). These include reference compound 2, unsubstituted at the bay positions, four isomeric PDI bearing two cyanobenzene substituents (compounds 3-6), compounds $\mathbf{7}$ and $\mathbf{8}$, corresponding to compounds $\mathbf{3}$ and $\mathbf{4}$ with anisoles replacing cyanobenzenes, and the tetra-anisole-substituted PDI, compound 9. This choice of derivatives has enabled us to test the effects on the mentioned optical and photophysical observables of the electronic nature of bay substituents, namely electron-attracting (cyanobenzene) vs electron-donating (anisole), of trans (compounds 4,6,8) vs cis (compounds 3,5,7) disubstitution, of para- (compounds $\mathbf{3 , 4}$ ) vs meta- (compounds $\mathbf{5 , 6}$ ) cyanobenzene substitution, and of tetra- $v s$ dianisolesubstitution, compound 9 vs. compounds 7 and 8. Additionally, while most of the investigated bay-substituted PDI derivatives bear substituents connected to the perylene core through $\mathrm{O}$ atoms, in our compounds the phenyl moieties of the substituents are directly bound to the bay positions, thus enhancing the possibility of conjugative perylene core/aromatic substituent interactions. (TD-)DFT calculations of equilibrium geometries of reference compound $\mathbf{2}$, disubstituted compounds $3,4,7$ and $\mathbf{8}$ and tetrasubstituted 9 , as well as one-photon electronic spectra of $\mathbf{2}, \mathbf{3}, \mathbf{4}, \mathbf{7}$ and $\mathbf{8}$, taken as representative examples of cyanobenzene and anisole disubstituted perylene diimides, have provided grounds for a rationalization of the experimentally observed optical and photophysical properties. 


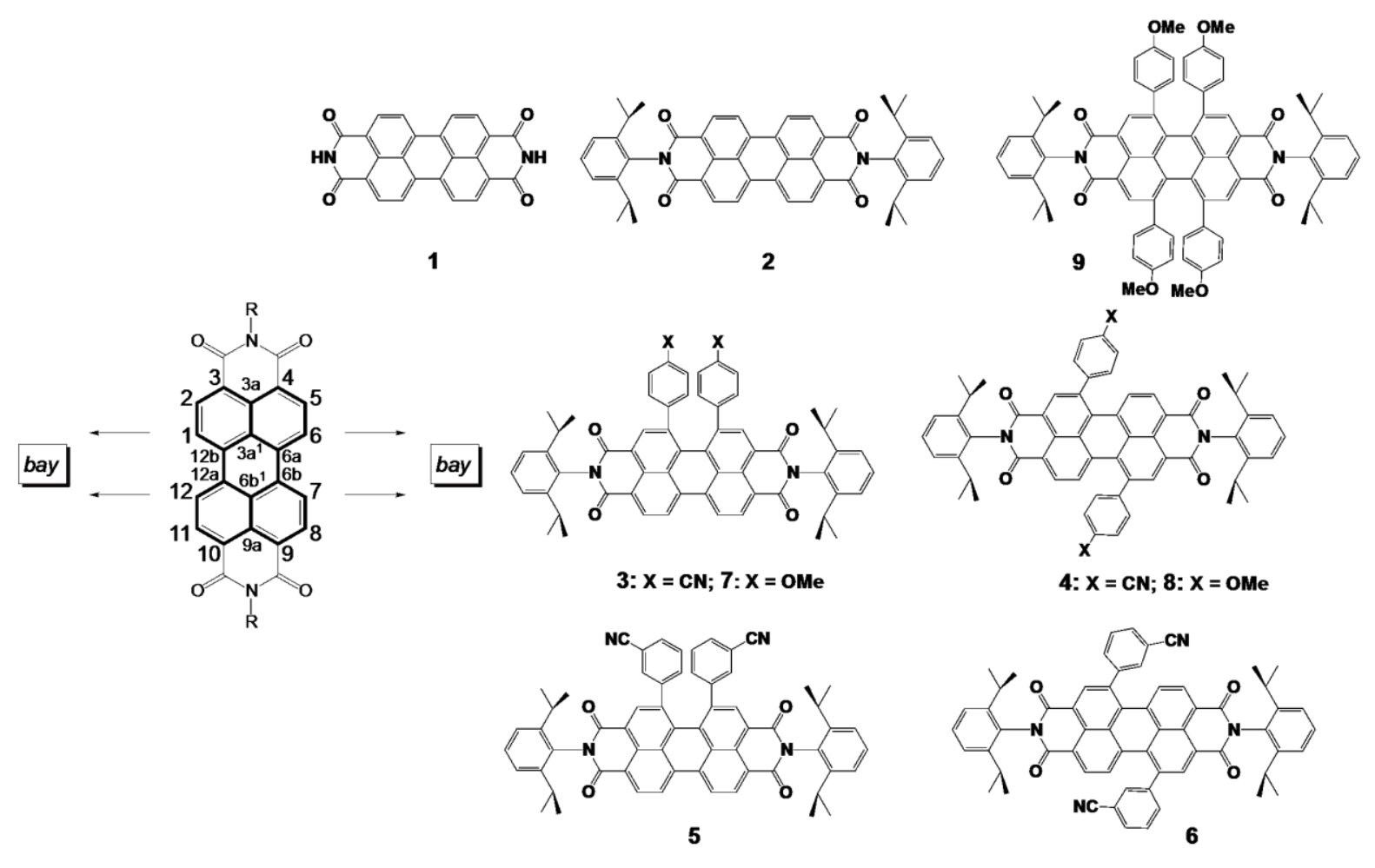

Figure 1. Investigated perylene diimides.

\section{Experimental and computational methods}

\subsection{Synthesis and product characterization}

Details on the synthesis and characterization of the bay-substituted perylenetetracarboxy-3,4:9,10diimides have been reported previously. ${ }^{32,33}$

\subsection{Computational details}

All the calculations were carried out using the Firefly Quantum Chemistry package, ${ }^{34}$ which is partially based on the GAMESS (US) source code. ${ }^{35}$ First, the geometry of molecules $\mathbf{2}, \mathbf{3}, \mathbf{4}$ and 7-9 were fully optimized at the b3lyp/6-31 $\mathrm{g} *$ level checking for the positive-semidefinite character of the hessian in order to ensure that the stationary points were true local minima. On the basis of circular dichroism spectroscopic evidence, ${ }^{33} \mathrm{C}_{2}$ and $\mathrm{D}_{2}$ symmetries were assumed, respectively, for the disubstituted derivatives on one hand and the tetrasubstituted, 9, on the other. $\mathrm{C}_{2 \mathrm{~h}}$ and $\mathrm{C}_{2 \mathrm{v}}$ symmetries were tested for the bay-unsubstituted compound 2. Starting from these gas-phase optimized structures, the one-photon absorption (OPA) spectra were obtained for the first five systems in the framework of adiabatic LR-TDDFT at the b3lyp/6-31g* level including the solvation effect as implemented in the C-PCM model. ${ }^{36-38}$ It is worth noting that the solvation energy was calculated considering only the electrostatic contribution. For the sake of comparison 
with OPA experimental data, the parameters selected for the evaluation of the solvent effect corresponded to cyclohexane and acetonitrile.

\subsection{Absorption and fluorescence measurements}

One-photon absorption spectra were measured with a Cary $100 \mathrm{UV}$-visible spectrophotometer using $1 \mathrm{~cm}$ quartz cuvettes. Steady-state fluorescence spectra were obtained on a Spex Jobin-Yvon FluoroMax3 spectrofluorometer and were corrected for the spectral sensitivity of the excitation and the emission channels. Emission quantum yields, $\Phi_{\mathrm{F}}$, were determined at $\mathrm{T}=20-25^{\circ} \mathrm{C}$ using different standards, whose choice was dependent on the absorption and emission features of the analyzed compounds, as reported in Table 1 . In particular, we used fluorescein in $\mathrm{NaOH} 0.1 \mathrm{M}\left(\Phi_{\mathrm{F}}\right.$ $\left.=0.925^{39}\right)$, rhodamine $\mathrm{B}$ in ethanol $\left(\Phi_{\mathrm{F}}=0.65^{40}\right)$ and cresyl violet in methanol $\left(\mathrm{A}^{\max }=0.10-0.18\right.$, $\Phi_{\mathrm{F}}=0.64^{41}$ ). The standard correction for the refractive index of the solvents was introduced. Luminescence lifetimes were measured with an IBH-5000 and a Horiba FluoroMax4 timecorrelated single-photon counting equipments using excitation wavelengths within the intense lowest-energy absorption bands, namely, $574 \mathrm{~nm}$ for compound $\mathbf{3}, 510 \mathrm{~nm}$ for 4, $570 \mathrm{~nm}$ for 7 and 8 and $631 \mathrm{~nm}$ for $\mathbf{9}$. Laser flash photolysis experiments were performed on compound $\mathbf{8}$ in acetonitrile using the second harmonic of a Nd-YAG laser (532 nm, ca. $10 \mathrm{~ns}$ FWHM) as the excitation source, and a monochromator set in the 400-600 $\mathrm{nm}$ range with a photomultiplier ( $2 \mathrm{~ns}$ resolution) as the detection system. Dithiacarbocyanine iodide in methanol was used as a reference system. ${ }^{42}$ Measurements were performed on samples with matched absorbances of about 0.8 at $532 \mathrm{~nm}$. Both emission and transient absorption experiments were performed on PDI solutions deoxygenated by nitrogen bubbling.

\subsection{Two-photon absorption}

Two-photon-excited fluorescence experiments (2PEF) were performed using a mode-locked Ti : sapphire laser generating $150 \mathrm{fs}$-wide pulses at a repetition rate of $76 \mathrm{MHz}$, with a time-averaged power of several hundreds of $\mathrm{mW}$ (Coherent Mira 900 pumped by a $5 \mathrm{~W}$ Verdi). The laser light (700-920 nm) was attenuated using a combination of half-wave plates and a Glan-laser polarizer. Alternatively, the Ti:sapphire laser pumped an optical parametric oscillator (Coherent/APE OPO PP-Automatic), for generation of excitation light in the range 990-1200 $\mathrm{nm}$. The excitation power was controlled using neutral density filters of varying optical density mounted in a computercontrolled filter wheel. After five-fold expansion through two achromatic doublets, the laser beam was focused by a microscope objective (10x, NA 0.25 , Olympus, Japan) into a standard $1 \mathrm{~cm}$ absorption cuvette containing $10^{-4} \mathrm{M}$ solutions of the sample in acetonitrile. The fluorescence from the sample was collected in epifluorescence mode, through the microscope objective, and reflected by a dichroic mirror (Chroma Technology Corporation, USA; "blue"' filter set: 675dcxru; "red" 
filter set: $780 \mathrm{dxcrr}$ ). This makes it possible to avoid the inner filter effects related to the high dye concentrations used $\left(10^{-4} \mathrm{M}\right)$ by focusing the laser near the cuvette window. Residual excitation light was removed using a barrier filter (Chroma Technology; “blue'”: e650-2p, "red”: e750sp$2 \mathrm{p}$ ). The fluorescence was coupled into a $600 \mu \mathrm{m}$ multimode fiber by an achromatic doublet. The fiber was connected to a compact CCD-based spectrometer (BTC112-E, B\&WTek, USA), which measured the two-photon excited emission spectrum. The emission spectra were corrected for the wavelength-dependence of the detection efficiency using correction factors established through the measurement of reference compounds having known fluorescence emission spectra. 2PA crosssections $\left(\sigma_{2}\right)$ were determined from the two-photon excited luminescence cross-sections $\left(\sigma_{2} \Phi_{\mathrm{F}}\right)$ and the luminescence emission quantum yield $\left(\Phi_{\mathrm{F}}\right)$ according to the method described by $\mathrm{Xu}$ and Webb. ${ }^{43}$ For the $720-920 \mathrm{~nm}$ excitation window, $10^{-4} \mathrm{M}$ fluorescein in $0.01 \mathrm{M} \mathrm{NaOH}(\mathrm{aq})$ was used as a reference, applying corrections for the refractive index of the solvent. ${ }^{44}$ For measurements with excitation in the 990-1200 $\mathrm{nm}$ range, we used Nile Red in DMSO $\left(10^{-4} \mathrm{M}\right)$ as a secondary reference. ${ }^{45}$ Its values were calibrated using the reference values given by Makarov, Drobizhev and Rebane for rhodamine $\mathrm{B}$ in methanol, fluorescein in $0.01 \mathrm{M} \mathrm{NaOH}(\mathrm{aq})$ and Styryl-9M in $\mathrm{CHCl}_{3 .}{ }^{46}$ The quadratic dependence of the luminescence intensity on the excitation power was checked for each sample and all wavelengths, indicating that the measurements were carried out in intensity regimes where saturation or photodegradation did not occur.

All measurements were carried out at room temperature $\left(20-25^{\circ} \mathrm{C}\right)$ using spectroscopic quality organic solvents.

\section{Results}

\subsection{Synthetic strategy}

We comment here on the synthetic strategies devised to obtain the bay-substituted perylenetetracarboxy-3,4:9,10-diimides in Figure 1. Synthetic details have been reported elsewhere. ${ }^{32,33}$ Electrophilic substitutions in the bay postitions of perylenetetracarboxy-3,4:9,10dianhydride are favoured and compounds $\mathbf{1 0}$ and $\mathbf{1 3}$ (see Figure 2) are obtained by halogenation of the unsubstituted precursors. The 1,6-dichloroperylenetetracarboxy-3,4:9,10-diimide 15 was not available by direct halogenation of the corresponding dianhydride and consecutive transformation into the diimide. This derivative was obtained by partial dehalogenation of the 1,6,7,12tetrahalogenated compound 14. ${ }^{33,47}$ Suzuki-Miyaura reactions were then carried out with the perylenediimid derivatives 11, 14 and 15 in order to introduce the aryl substituents in the corresponding bay positions. This was easily done in the case of the 1,7-dibromo 
perylenetetracarboxy-3,4:9,10-diimide 11. Thus compounds 4, 6 and $\mathbf{8}$ (general structure 12) were prepared.
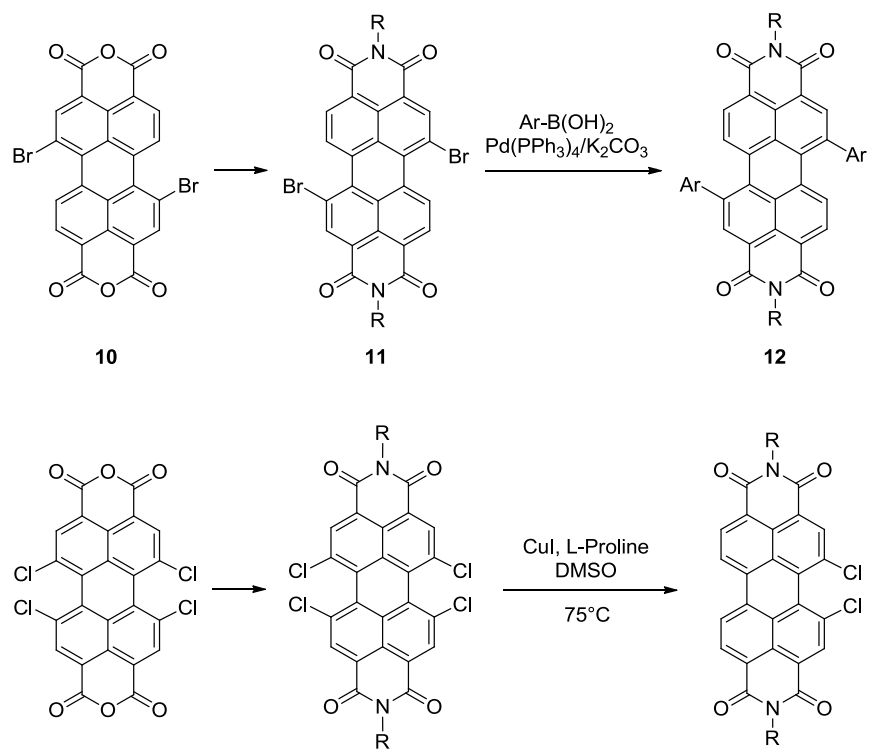

13

14

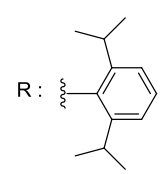

$\mathrm{Ar}-\mathrm{B}(\mathrm{OH})_{2}$ $\mathrm{Ar}-\mathrm{B}(\mathrm{OH})_{2}$
$\mathrm{Pd}\left(\mathrm{PPh}_{3}\right)_{4} / \mathrm{K}_{2} \mathrm{CO}_{3}$

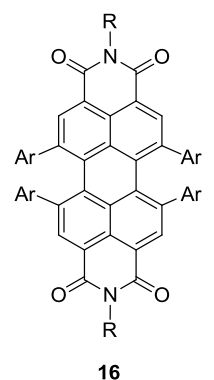

15
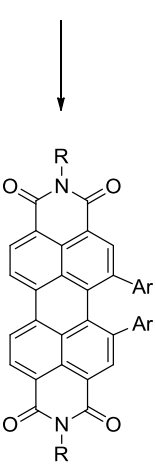

17

Figure 2. Synthetic routes to bay di-and tetra-substituted PDI.

As already pointed out, a number of perylenetetracarboxy-2,4:9,10-diimides with O-alkoxy or Oaryl substituents in the bay positions 1, 6, 7 and 12 have been synthesized for different purposes. Establishing a C-C bond in all 4 bay positions using the Suzuki-Miyaura reaction turned out to be more difficult. ${ }^{32,33,48}$ Compound 9 as well as other compounds of general structure 16 were obtained in this way from precursor 14. Suzuki-Miyaura reactions of 1,12dihalogenoperylenetetracarboxy-2,4:9,10-diimides such as $\mathbf{1 5}$ were also difficult to obtain. Characteristic side reactions have also been studied in this context. However, some corresponding diaryl derivatives $\mathbf{1 7}$ such as $\mathbf{3}, \mathbf{5}$ and $\mathbf{7}$ were synthesized by this method. ${ }^{33}$ 


\subsection{One-photon absorption}

\subsubsection{Lowest-energy band}

Reference compound 2 features a lowest-energy absorption band strongly reminiscent of the corresponding band of perylene (Figure 3). In particular, the two bands feature a similar, wellresolved vibrational structure with comparable vibronic spacings, $\sim 1450$ and $\sim 1500 \mathrm{~cm}^{-1}$, for compound 2 and perylene, respectively, attributable to a totally-symmetric ${ }^{49}$ breathing type mode 50 of the perylene moiety. In spite of the extremely low solubility of terminally unsubstituted compound 1 in all common solvents, we could measure its absorption and fluorescence excitation spectra in dimethylsulfoxide, and found a band with shape and position very similar to those of the corresponding band of compound 2 (Figure 3). Thus, the end 2,6-diisopropylphenyl substituents cause no relevant change in band position or shape, a finding related with both the quasiorthogonality of the xylene planes to the perylene-diimide core and the occurrence of nodes at the imide nitrogens in the HOMO and LUMO of the reference chromophore, compound 1. ${ }^{27}$ The structured visible absorption band of compounds $\mathbf{1}$ and $\mathbf{2}$ is the equivalent of the $435 \mathrm{~nm}$ band of perylene that is essentially due to the long-axis-polarized transition from the ground state $\left({ }^{1} \mathrm{Ag}_{\mathrm{g}}\right)$ to the singly excited ${ }^{1}(\mathrm{HOMO}, \mathrm{LUMO})$ configuration $\left({ }^{1} \mathrm{~B}_{3 \mathrm{u}}\right)$, named $\mathrm{p}$ and ${ }^{1} \mathrm{~L}_{\mathrm{a}}$ in the Clar and in the Platt notations. The bathochromic shift and the intensity increase found for this band of compounds 1 and $\mathbf{2}$ with respect to that of perylene result from conjugative interactions between the perylene core and the bisimide moieties that are related with retention of the planar centrosymmetrical structure $\left(D_{2 h}\right)$ of the perylene core in the two diimides.

The marked changes in the absorption spectra observed on moving from reference compound 2 to the disubstituted compounds, 3, 4, 7 and $\mathbf{8}$ (see Figure 3 and Table 1), a set of compounds that encompasses both a change in the chemical nature of the substituents (electron-withdrawing cyanobenzene $v s$ electron-donating anisole) and in the substitution topology (trans vs cis), can be seen as the combined result of substituent inductive and conjugative effects, modulated by changes in the equilibrium geometries, and of symmetry reduction.

Concerning the lowest-energy intense band, we observe a general blurring of the vibronic structure and a bathochromic shift that is more marked for anisole-disubstituted compounds (7 and 8) than for the corresponding cyanobenzene-disubstituted compounds (3-6), and for the cis (3(5) and 7) than for the trans $(\mathbf{4 ( 6 )}$ and $\mathbf{8})$ arrangement of the substituents. The latter effect recalls the more or less markedly red-shifted absorptions of cis vs trans $\pi$-conformers of conjugated systems (e.g. polyenes). By analogy with the basic case of trans and cis butadiene, the bathochromic absorption shifts of derivatives 3 and 7 with respect to $\mathbf{4}$ and $\mathbf{8}$ might be attributed to different electron-electron interactions operative in the cis and in the trans conformers. ${ }^{51}$ In the present case, however, an 
additional specific reason for the observed red-shifted absorption of a cis isomer relative to the corresponding trans one could be the less twisted arrangements consistently adopted by the substituent rings in the former relative to the latter (see later on).

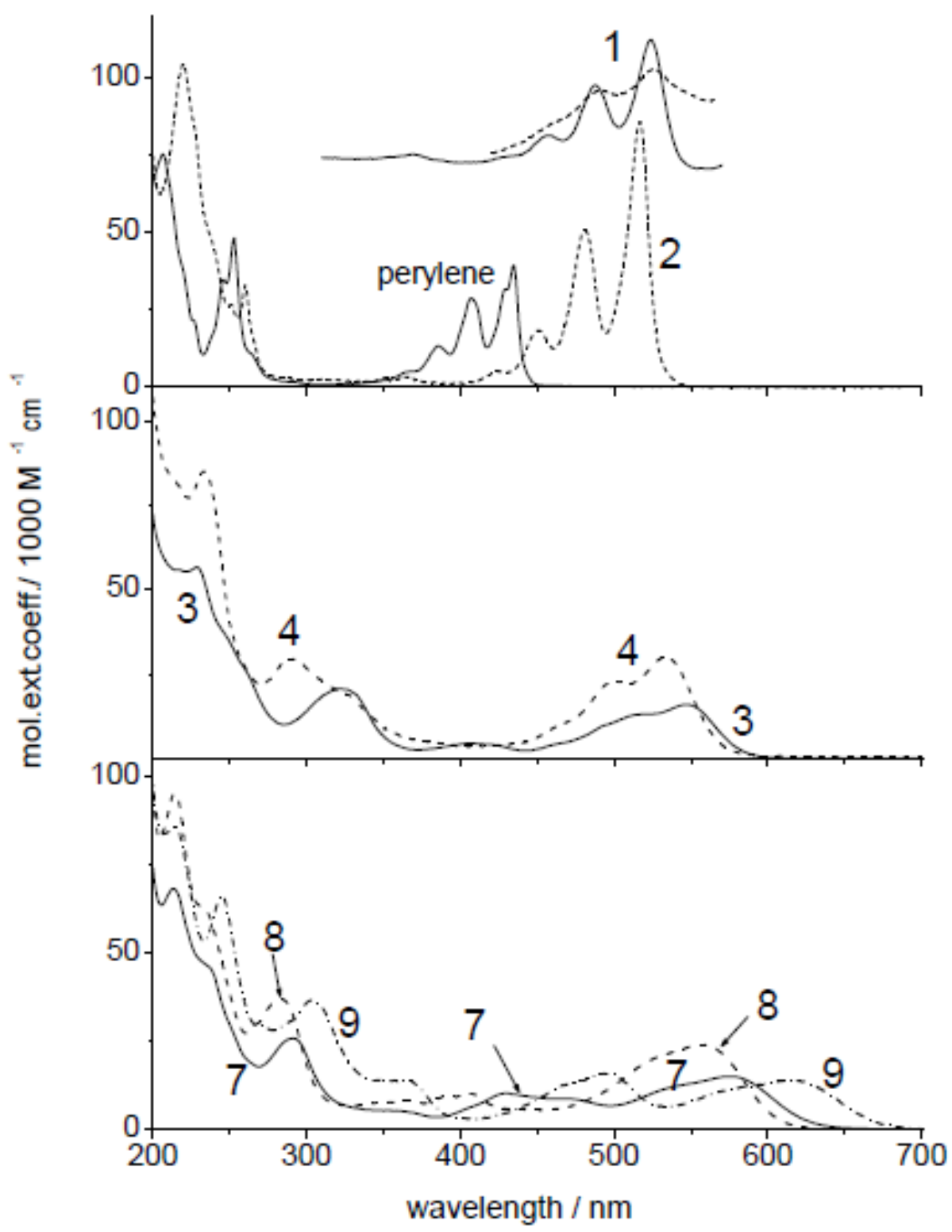

Figure 3. Top: absorption spectra of perylene and $\mathbf{2}$ in cylohexane and absorption (dotted line) and fluorescence excitation spectra of $\mathbf{1}$ in DMSO. Centre and bottom: absorption spectra of 3, 4, 7, 8 and 9 in cyclohexane. The extinction coefficients of $2,3,4,7,8$ and 9 were determined in acetonitrile, because of the scanty solubilities of these compounds in cyclohexane; the extinction coefficients of $\mathbf{1}$ could not be determined because of an extremely low solubility in all solvents. 
The mentioned differences in the vibronic structure blurring are connected with differences in geometry (see later on) and in the electronic nature of the substituents. Such a blurring may originate in the excitation of low-frequency twisting modes of the interanular substituent-core bonds, in close analogy with the absorption spectra of conjugated compounds bearing more-or-less sterically-hindered phenyl substituents. ${ }^{52}$ In a topic case, the cis stereoisomers of $\alpha, \omega-$ diphenylpolyenes, this interpretation gained theoretical support by explicit calculations of the $S_{0}$ and $S_{1}$ potential energy curves and Franck-Condon distributions. ${ }^{53}$ On the other hand, blurring of the vibronic structure in the spectra of PDI has been closely associated with distortion of the perylene core with large twist angles between its naphthalene units. ${ }^{54}$ Thus, the more resolved structure exhibited by cyanobenzene derivatives, $\mathbf{3}$ and $\mathbf{4}$, with respect to the three anisole derivatives, 7, 8 and $\mathbf{9}$, (Figure 3) can indicate a more pronounced distortion out of planarity of the perylene core for the latter derivatives and/or a reduced conformational freedom of the cyanobenzene relative to the anisole substituents. At variance with reference compound, 2, analysis of the vibronic structure of the lowest-energy absorption bands of compounds $3,4,7,8$ and 9 in cyclohexane (see Figure SI1 in the electronic supplementary information) reveals structures that are not always regular and, thus, variable spacings. The spacings between the first two vibronic bands range between 1150 and $1400 \mathrm{~cm}^{-1}$ with, apparently, no clear correlation with the substituent nature and the substitution pattern.

The lowest-energy, intense bands of anisole-disubstituted diimides $\mathbf{7}$ and $\mathbf{8}$ are bathochromically shifted with respect to the corresponding cyanobenzene-disubstituted diimides $\mathbf{3}$ and $\mathbf{4}$, a finding that indicates a stronger conjugation between the anisole substituents and the perylene core. The observation that meta-disubstituted cyanobenzene compounds $\mathbf{5}$ and $\mathbf{6}$ have essentially the same absorption spectra down to $250 \mathrm{~nm}$ as the corresponding para-disubstituted derivatives 3 and 4 suggests small conjugation between the cyanobenzene substituents and the perylene core. Thus, the bathochromic shifts of the cyanobenzene-substituted compounds relative to reference compound $\mathbf{2}$ are mainly attributable to inductive effects. The tetra-anisole-substituted compound $\mathbf{9}$ exhibits a marked further bathochromic shift of the lowest-energy absorption band relative to the corresponding disubstituted compounds, $+41 \mathrm{~nm}$ relative to cis compound $7,+59 \mathrm{~nm}$ relative to trans compound $\mathbf{8}$, all in cyclohexane. These shifts are comparable with the shifts caused by anisole disubstitution, +58 and $+40 \mathrm{~nm}$ for compounds $\mathbf{7}$ and $\mathbf{8}$ relative to reference compound $\mathbf{2}$. This finding is consistent with conservation of pronounced conjugative effects of the four anisole substituents in compound 9, thus, again, with a non-perpendicular geometry of the anisole substituents relative to the local perylene-core planes in spite of the substituent crowding in this derivative. The lowest-energy absorption band of compound $\mathbf{9}$ (maximum at $635 \mathrm{~nm}$ in acetonitrile) 
is markedly bathochromically shifted with respect to the corresponding band of a similar tetraphenoxy-substituted PDI (maximum at $582 \mathrm{~nm}$ in dichloromethane). ${ }^{28,50,55}$ Although the positions of these bands are likely affected by differences in the ground-state geometries, yet this finding points to much larger conjugative effects of our anisole substituents, with their phenyl rings directly bound to the perylene core, with respect to phenoxy substituents linked through $\mathrm{O}$ atoms. All substituted derivatives, irrespective of the nature of the substituents and of their cis or trans arrangement, feature quite markedly reduced oscillator strengths of the lowest-energy absorption bands with respect to the reference perylene diimide, 2. A parallelism can be found in the data in Table 1 between the bathochromic-shift and the oscillator-strength decrease. In fact, the transdisubstituted compounds, $\mathbf{4}$ and $\mathbf{8}$, have more intense and hypsochromically shifted lowest-energy bands with respect to the corresponding cis-derivatives (3 and 7), and the anisole-substituted derivatives have bathochromically shifted and slightly but consistently lower oscillator strengths and radiative rate constants relative to the corresponding cyanobenzene-substituted derivatives. Finally, the tetrasubstituted compound 9 features the most red-shifted and the weakest lowestenergy band. As an internal consistency check, we observe that, in all cases investigated, larger oscillator strengths go parallel with higher radiative rate constants.

For many compounds, spectra and fluorescence quantum yields and lifetimes were also measured in polar solvents, in order to test the effects of electrostatic and hydrogen bonding solute-solvent interactions on these observables. As shown in Table 1, reference compound 2, the pcyanobenzene-disubstituted derivatives, $\mathbf{3}$ and $\mathbf{4}$, and the three anisole-substituted derivatives, $\mathbf{7 ,} 8$ and 9, exhibit a small positive absorption solvatochromism, respectively -220, -330, -410, -360, 410 and $-490 \mathrm{~cm}^{-1}$ shifts from cyclohexane to acetonitrile. This suggests the occurrence of small changes in the electric dipole moments between the ground and lowest-excited singlet states. The spectroscopic effects of the protic nature of methanol $v s$ aprotic acetonitrile, i.e., of solute/solvent hydrogen bonding, are negligible. 
Table 1. Absorption and emission maxima, experimental oscillator strengths (f), Stokes shifts (SS), fluorescence lifetimes and quantum yields $\left(\Phi_{\mathrm{F}}\right)$, radiative and overall non-radiative decay rate constants of compounds 2-9. dmso: dimethylsulfoxide, cx: cyclohexane, acn: acetonitrile, MeOH: methanol.

\begin{tabular}{|c|c|c|c|c|c|c|c|c|c|}
\hline & & $\lambda^{\mathrm{abs}}{ }_{\max } * / \mathrm{nm}$ & $\mathrm{f} \lambda$ & $\lambda^{\mathrm{em}_{\max }} / \mathrm{nm}$ & $\mathrm{SS} / \mathrm{cm}^{-1}$ & $\tau / \mathrm{ns}$ & $\Phi_{\mathrm{F}}$ & $\mathrm{k}_{\mathrm{r}} / 10^{7} \mathrm{~s}^{-1}$ & $\mathrm{k}_{\mathrm{nr}} / 10^{7} \mathrm{~s}^{-1}$ \\
\hline 1 & dmso & 524 & & 536 & & & & & \\
\hline \multirow[t]{3}{*}{2} & $\mathrm{cx}$ & 517 & 0.56 & 521 & 149 & 3.6 & $0.95^{\mathrm{a}}$ & 26.4 & $\sim 1$ \\
\hline & acn & $523(86)$ & & 533 & 359 & 3.8 & $0.98^{\mathrm{a}}, 1.00^{\mathrm{b}}$ & 25.8 & $\sim 0.5$ \\
\hline & $\mathrm{MeOH}$ & 525 & & 539 & 495 & 4.2 & $0.95^{\mathrm{a}}$ & 22.6 & $\sim 1$ \\
\hline \multirow[t]{2}{*}{3} & $\mathrm{cx}$ & 547 & 0.22 & 601 & 1650 & 8.9 & $0.95^{\mathrm{b}}$ & 10.7 & 0.6 \\
\hline & acn & $557(16)$ & & 624 & 1930 & 9.1 & $0.67^{b}$ & 7.4 & 3.6 \\
\hline \multirow[t]{3}{*}{4} & $\mathrm{cx}$ & 533 & 0.39 & 575 & 1370 & 6.4 & $0.82^{\mathrm{c}}$ & 12.7 & 2.8 \\
\hline & acn & $545(31)$ & & 594 & 1510 & 7.1 & $0.85^{\mathrm{c}}, 0.83^{\mathrm{b}}$ & 11.8 & 2.4 \\
\hline & $\mathrm{MeOH}$ & 546 & & 592 & 1420 & 6.7 & $0.79^{c}$ & 11.7 & 3.1 \\
\hline 5 & acn & $554(29)$ & & 621 & 1950 & 8.7 & $0.73^{\mathrm{b}}$ & 8.4 & 3.1 \\
\hline 6 & acn & $545(39)$ & & 591 & 1430 & 6.8 & $0.86^{\mathrm{b}}$ & 13.0 & 2.1 \\
\hline \multirow[t]{3}{*}{7} & $\mathrm{cx}$ & 575 & 0.19 & 665 & 2350 & 8.6 & $0.53^{b}$ & 6.2 & 5.5 \\
\hline & acn & $587(15)$ & & 727 & 3280 & 1.7 & $0.052^{b}$ & 3.1 & 56 \\
\hline & $\mathrm{MeOH}$ & 591 & & 737 & 3350 & 0.45 & $0.012^{\mathrm{b}}$ & 2.7 & 215 \\
\hline \multirow[t]{3}{*}{8} & $\mathrm{cx}$ & 557 & 0.34 & 622 & 1880 & 8.4 & $0.97^{b}$ & 11.5 & $\sim 0.4$ \\
\hline & acn & $570(24)$ & & 685 & 2950 & 2.7 & $0.13^{b}$ & 4.8 & 32.2 \\
\hline & $\mathrm{MeOH}$ & 572 & & 700 & 3200 & 0.6 & $0.02^{b}$ & 3.3 & 163 \\
\hline \multirow[t]{3}{*}{9} & $\mathrm{cx}$ & 616 & 0.17 & 692 & 1780 & 10.6 & $0.55^{b}$ & 5.2 & 4.2 \\
\hline & acn & $635(14)$ & & 735 & 2140 & 4.1 & $0.15^{b}$ & 3.7 & 20 \\
\hline & $\mathrm{MeOH}$ & 640 & & 745 & 2200 & 1.2 & $0.04^{\mathrm{d}}$ & 3.3 & 80 \\
\hline
\end{tabular}

*Within parentheses: maximum extinction coefficients $/ 10^{3} \mathrm{M}^{-1} \mathrm{~cm}^{-1}$ and, for selected compounds, oscillator strengths ; ${ }^{\mathrm{a}}$ Ref: fluorescein in $\mathrm{NaOH} 0.1 \mathrm{M}, \Phi_{\mathrm{F}}=0.925,{ }^{\mathrm{b}}$ Ref: cresyl violet in methanol, $\mathrm{A}^{\mathrm{max}}=0.10-0.18 \Phi_{\mathrm{F}}=0.64$, ${ }^{\mathrm{c}}$ Ref: rhodamine $\mathrm{B}$ in ethanol $\Phi_{\mathrm{F}}=0.65,{ }^{\mathrm{d}}$ Ref: compound 9 in acetonitrile, $\Phi_{\mathrm{F}}=0.15 . \mathrm{T}=20-25{ }^{\circ} \mathrm{C}$. 


\subsubsection{Higher-energy transitions}

The similarity of the spectra of compound $\mathbf{2}$ and perylene extends to higher-energy transitions. A very weak absorption band of perylene around $325 \mathrm{~nm}\left(\alpha /{ }^{1} \mathrm{~L}_{\mathrm{b}}\right.$ according to the Clar/Platt notations, too weak to be visible in Figure 3) has its counterpart in a weak band with maximum at $~ 370 \mathrm{~nm}$ in the spectrum of compound 2. Moving to higher energies, the quite complex, intense band of compound 2 with onset at $\sim 270 \mathrm{~nm}$ reasonably corresponds to the intense band system of the perylene spectrum that covers about the same region and can be attributed to $\beta /{ }^{1} \mathrm{~B}_{\mathrm{b}}$ and $\beta{ }^{\prime} /{ }^{1} \mathrm{~B}_{\mathrm{a}}$ type transitions. This spectral similarity confirms that the perylene-like compounds $\mathbf{1}$ and $\mathbf{2}$ retain the high symmetry $\left(\mathrm{D}_{2 h}\right)$ of the unsubstituted chromophore.

The main change caused by bay substitutions in the higher-energy region ( $250 \mathrm{~nm}<\lambda<480 \mathrm{~nm}$ ) of the spectra in Figure 3 is the higher absorption intensities of the bay-substituted compounds, $\mathbf{3}$, 4, 7, 8 and 9 relative to reference compound 2. In this region, cyanobenzene-disubstituted compounds, 3 and 4, exhibit relatively strong absorptions between 300 and $360 \mathrm{~nm}$. On the other hand, substitution topology is crucial in causing trans-disubstituted derivatives, $\mathbf{4}$ and $\mathbf{8}$, to feature higher intensities than cis-disubstituted ones in the 200-300 nm region. Finally, the tetrasubstituted compound 9 features a remarkably high intensitity for the second absorption band with maximum at $493 \mathrm{~nm}$. This turns out to be as intense as the lowest-energy band of the same compound and twice as intense as the corresponding band systems with maxima, respectively, at 432 and $407 \mathrm{~nm}$ of the disubstituted 7 and $\mathbf{8}$. Combined with the lowest-energy band with maximum at $616 \mathrm{~nm}$, it covers the entire visible region and produces the grey/black colour of the solutions of this PDI. Apart from a red-shift of 15-20 nm, the spectrum of this compound below $350 \mathrm{~nm}$ reproduces the spectrum of the trans disubstituted derivative $\mathbf{8}$.

A simple Hückel-molecular-orbital (HMO) exercise can help assigning these higher-energy bands and provides a qualitative interpretation of the effects of bay substitution geometry, trans vs cis, on these portions of the spectra. We performed the analysis on three model chromophores of unsubstituted and trans and cis bay-disubstituted PDI, namely, perylene and trans and cis dianisole-perylene (Per-T and Per-C, see Figure 4). We describe here the main findings of the HMO analysis. A more detailed account of its results is provided in the electronic supplementary information. 


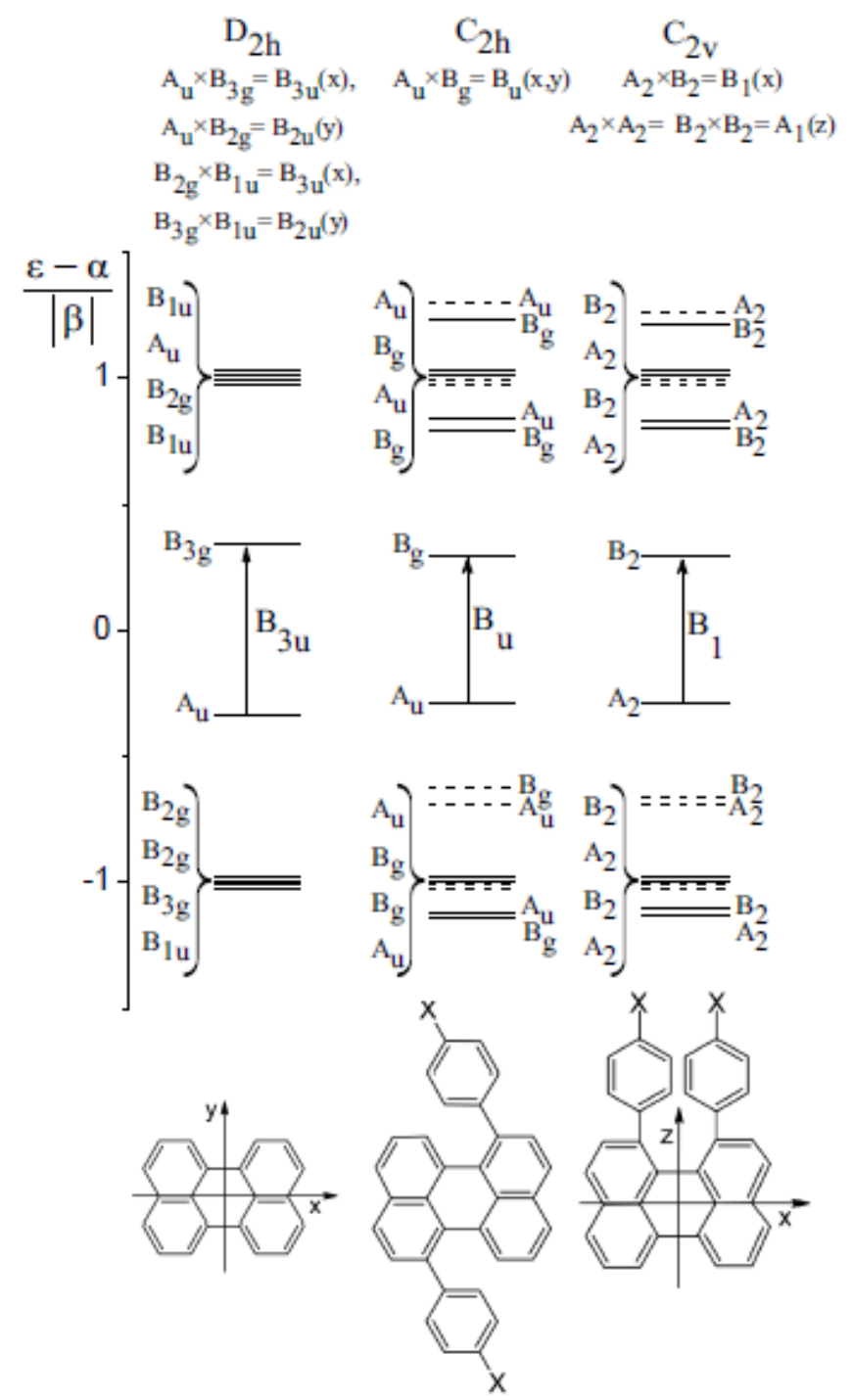

Figure 4. HMO energy diagrams for perylene (left) and trans- (centre) and cis- (right) anisoledisubstituted perylenes, Per-T and Per-C. $\mathrm{X}=\mathrm{OCH}_{3}$. (-): MOs mainly ( $>50 \%$ ) localized on the perylene core; (---): MOs mainly (>50\%) localized on the bay substituents.

The marked increase in intensity of the intermediate-energy bands for the anisole disubstituted derivatives (390-500 $\mathrm{nm}$ for 7 and 350-430 $\mathrm{nm}$ for 8) relative to the reference compound 2 (ca. 370 $\mathrm{nm}$ ) can be explained in terms of the larger number of allowed transitions in this region for the two former derivatives. This, in turn, derives from both symmetry reduction and the presence of additional molecular orbitals with significant anisole character. The bands with maxima at about 410 and $430 \mathrm{~nm}$, peculiar to the spectra of cis-disubstituted compounds $\mathbf{3}$ and 7, are reminiscent of the so-called cis-peaks of polyenic compounds. ${ }^{53}$ Moving to higher-frequency absorption regions, a similar explanation, i.e., an increase in the number of MOs combined with symmetry reduction, can be given to account for the higher intensities of disubstituted derivatives in the 260-360 nm region with respect to perylene and reference compound 2. 


\subsection{Two-photon absorption}

The two-photon absorption (2PA) spectra of compounds 2-9, measured in acetonitrile between ca 800 and ca $1200 \mathrm{~nm}$ by two-photon excited fluorescence, are shown in Figure 5 together with the corresponding portions of the one-photon spectra. The centrosymmetrical structure of the perylene diimide moiety ${ }^{56}$ causes the $2 \mathrm{PA}$ under the intense $\mathrm{S}_{0}-\mathrm{S}_{1}$ one-photon absorption band of compound 2 to be very weak, with cross-section values lower than about 2 GM in most of the investigated spectral range. These increase to $8 \mathrm{GM}$ from 850 to $800 \mathrm{~nm}$, i.e., at the long-wavelength onset of the one-photon forbidden transitions.

Consistently with the perpendicular geometry of the bay cyanobenzene substituents (see the following paragraph), $\sigma^{(2)}$ s were found almost null under the intense lowest-energy one-photon bands for the four disubstituted cyanobenzene derivatives 3-6. The 2PA cross section reached more measurable values, around $10 \mathrm{GM}$, for anisole disubstituted compounds $\mathbf{7}$ and $\mathbf{8}$, and for the tetrasubstituted compound, 9.

We measured higher 2PA at higher transition energies. Cross sections reaching about $80 \mathrm{GM}$ for all disubstituted derivatives 3-8 and around 180 GM for the tetrasubstituted compound 9 were found at the shortest excitation wavelength limit, 800 or $850 \mathrm{~nm}$ depending on the compound. This 2PA band likely corresponds to the $30 \mathrm{GM}$ band with maximum at 640-650 $\mathrm{nm}$ in the 2PA spectrum of perylene in dichloromethane. ${ }^{57}$ We notice that, due to the already discussed lack of conjugation between the cyanobenzene substituents and the perylene core, the meta-disubstituted cyanobenzene compounds, 5, 6, and the para-disubstituted ones, $\mathbf{3}$ and $\mathbf{4}$, have essentially the same 2PA spectra. On the other hand, the anisole disubstituted compounds, $\mathbf{7}$ and $\mathbf{8}$, exhibit a markedly more intense 2PA in the 850-1000 $\mathrm{nm}$ region than the cyanobenzene PDI. The cis dianisole derivative shows a significantly red-shifted $80 \mathrm{GM}$ absorption with respect to the trans one (ca. 850 vs ca. $800 \mathrm{~nm}$ ), in keeping with the general spectral red-shift of the electronic spectrum due to cis vs trans bay substitution. 


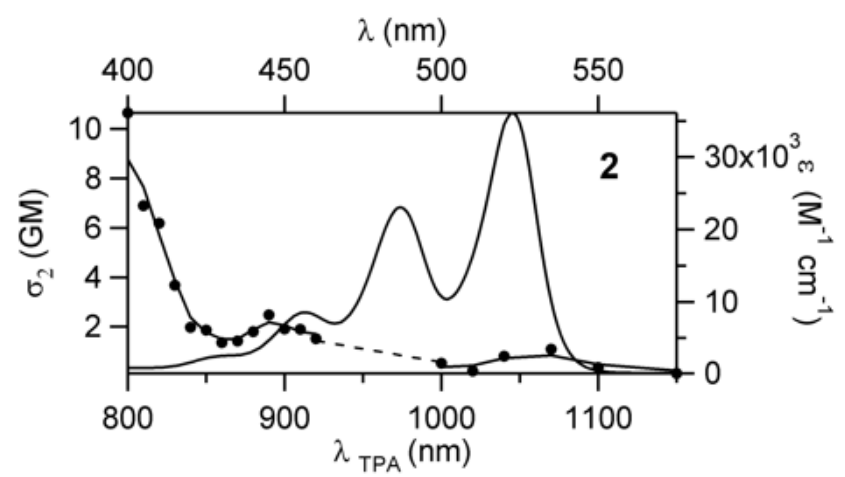

$\lambda(\mathrm{nm})$
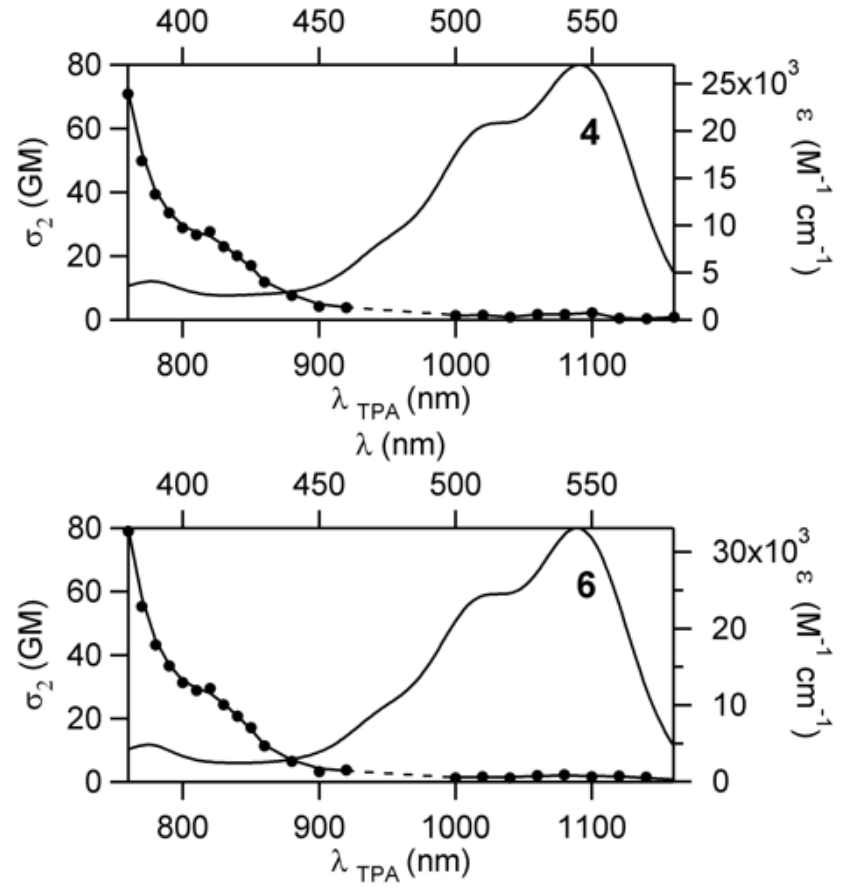

$\lambda(\mathrm{nm})$

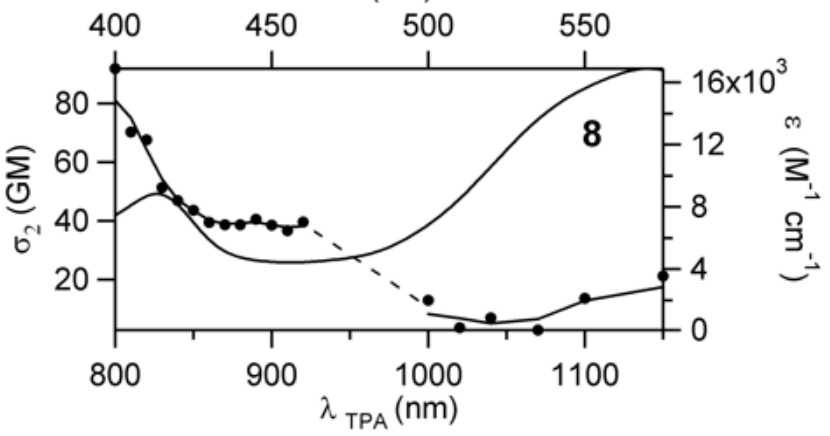

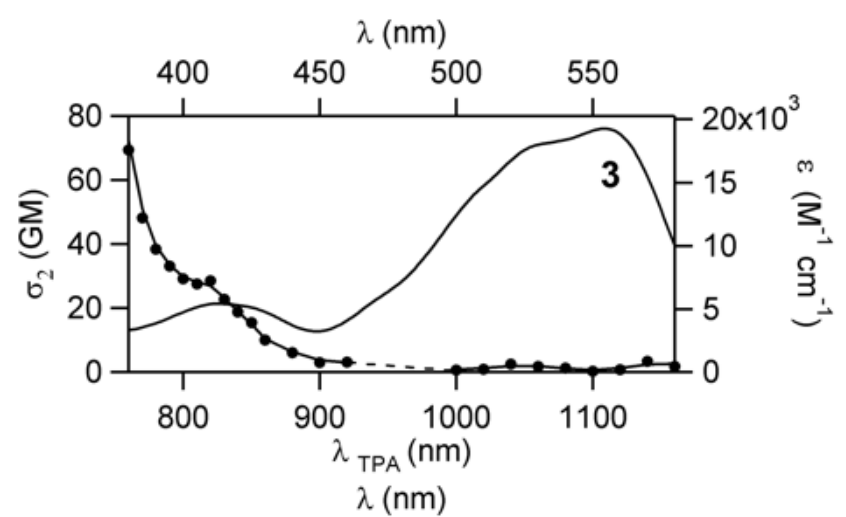
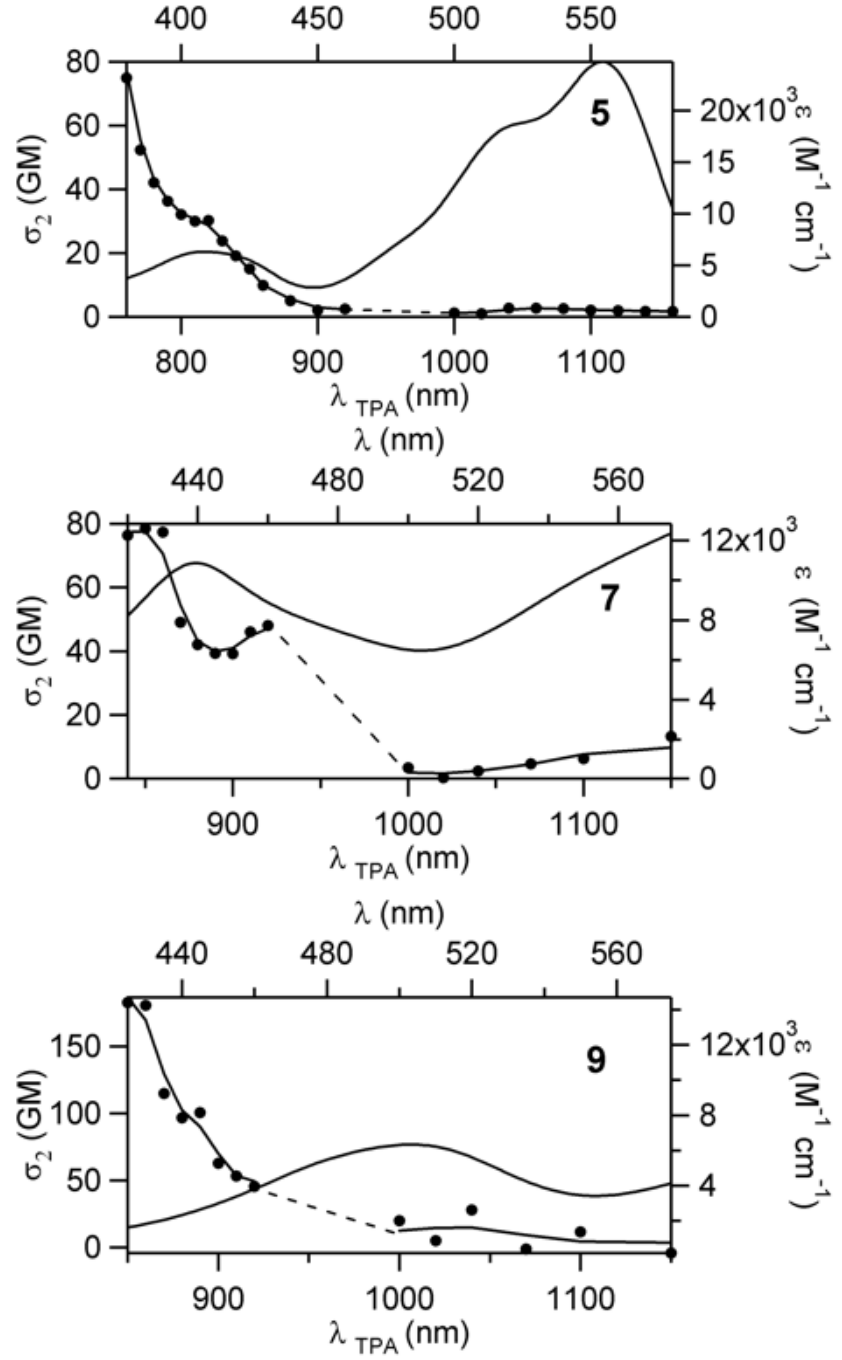

Figure 5. Two-photon absorption spectra of compounds 2-9 in acetonitrile. Solid lines represent linear absorption spectra, circles are experimental two-photon cross sections. 


\subsection{Theoretical results}

\subsubsection{Ground-state equilibrium geometries}

The gas-phase DFT equilibrium geometries of compounds 2, 3, 4, and 7-9 are depicted in Figure 6.

A planar perylene core was obtained with PDI 2 and 4. On the other hand, the perylene core was found quite markedly distorted out of planarity for all the other derivatives analyzed. At variance with the trans cyanobenzene disubstituted compound, $\mathbf{4}$, the perylene core of the corresponding anisole derivative, 8 , featured a propeller-like conformation, with the two almost planar naphthalene units twisted relative to each other by $17^{\circ}$. This value is slightly smaller than those found by molecular modelling and crystal X-ray diffraction studies for some tetraphenoxysubstituted PDI $\left(25-33^{\circ}\right),{ }^{50,54,55}$ but comparable with those of other PDI trans-disubstituted with two amino or with an amino and a nitro groups, ${ }^{58}$ and with carbazolyl functions. ${ }^{59}$

The cis disubstituted derivatives feature core deformations different from those of the corresponding trans derivatives but almost identical to each other. In both cases, the deformation is much more pronounced on the side of the substituents, likely as a mean to relieve steric hindrance, with twist angles between the local facing planes of the two almost planar naphthalene units of $30^{\circ}$ on the side of the substituted bay and $12^{\circ}$ on the other side. Furthermore, for the two cis derivatives, we find a slight 'opening' of the perylene core at the side of substitution, with an interconnecting $\mathrm{C}-\mathrm{C}$ bond length of 1.478 and $1.476 \AA$ for compounds 3 and 7, while the corresponding C-C bond lengths on the opposite, free side are, respectively, 1.467 and $1.468 \AA$. The C6a-C6b and C12a-C12b bond lengths are 1.473, 1.481, 1.476 and $1.474 \AA$ in compounds 2 , 4, 8 and 9, respectively. These findings are consistent with the idea that PDI can be considered as easily distorted assemblies of two naphthalene units connected by essentially single bonds. ${ }^{50}$ Finally, the crowded anisole tetrasubstituted compound, 9, shows a slightly more pronounced core deformation, with the two almost planar naphthalene units twisted by $31^{\circ}$ with respect to each other.

The difference in distortion of the perylene core between compounds 4 on one side, and $\mathbf{3}$ and 7-9 on the other goes together with a marked difference in the orientation of the phenyl planes of the bay substituents and the local perylene-core plane(s). The bay substituent phenyl rings were found normal to the core in the planar cyano-benzene derivative 4 , and to form angles of 44, 43, 59 and $43^{\circ}$ with the local planes of the core in the distorted derivatives 3 and 7-9. 


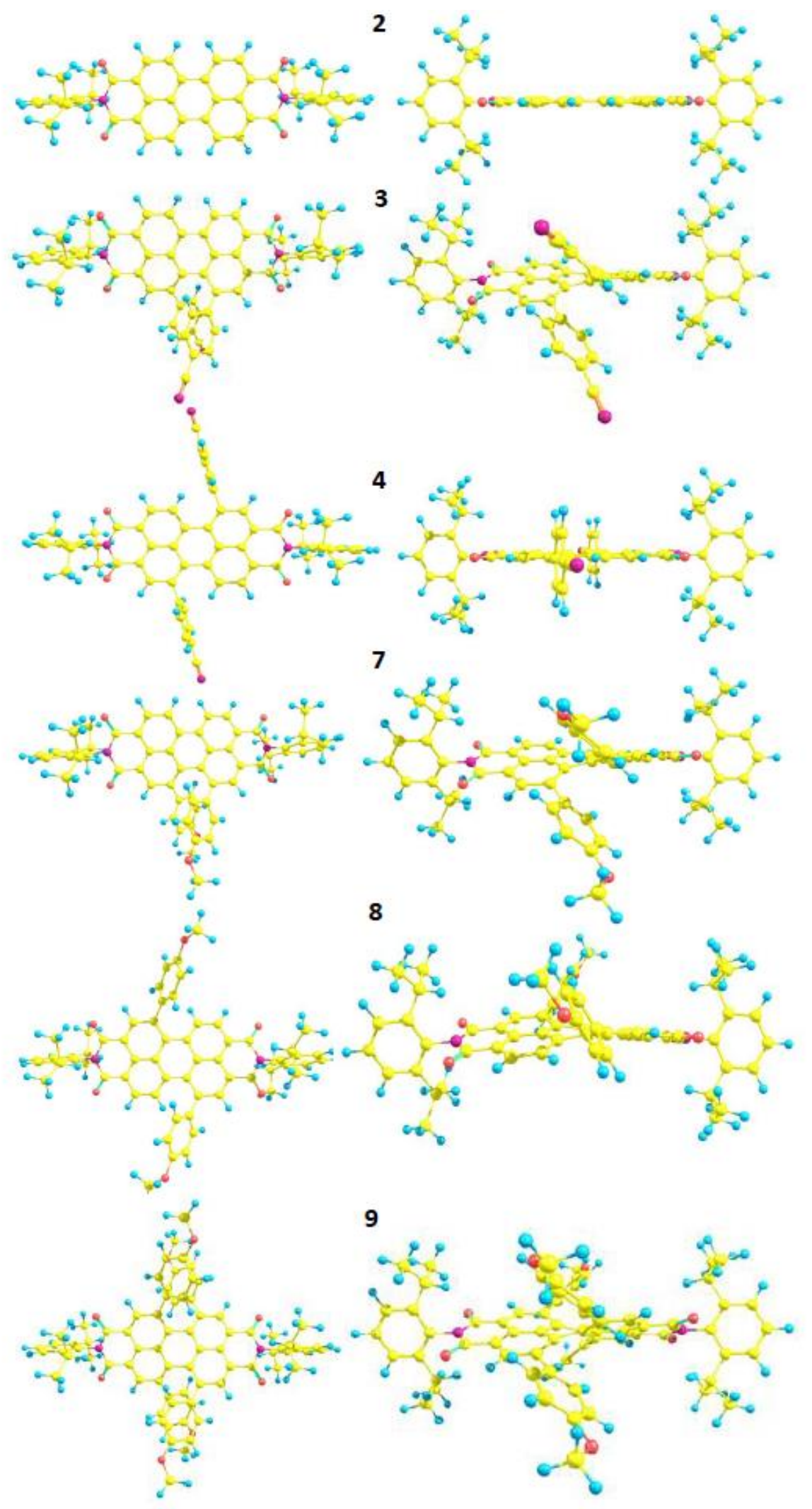

Figure 6. Top and side views of the ground-state equilibrium structures of compounds $\mathbf{2 , 4}$, and 79 in the gas phase. 
The less twisted geometry of the substituents in the cis disubstituted derivatives $\mathbf{3}$ and $\mathbf{7}$ relative to the corresponding trans derivatives, $\mathbf{4}$ and $\mathbf{8}$, suggests the occurrence of stronger substituent/perylene core conjugative interactions in the former and is consistent with the observed bathochromic shift of their lowest-energy absorption bands relative to the latter (Figure 3 and Table 1).

Concerning the terminal 2,6-diisopropylphenyl moieties, these were found to adopt conformations perpendicular to the perylene core (compounds 2 and 4 ) or to the local planes of the core. Only for reference compound $\mathbf{2}$, while a relative energy minimum was obtained with an arrangement of the 2,6-diisopropylphenyl substituents corresponding to a $\mathrm{C}_{2 \mathrm{~h}}$ molecular symmetry, an energy minimum lower than the previous one by $1.5 \mathrm{~kJ} \mathrm{~mol}^{-1}$ was found at a different isopropyl substituent geometry corresponding to an overall $\mathrm{C}_{2 \mathrm{v}}$ symmetry.

Molecular symmetry is reflected by the ground-state electric dipole moments of our compounds. All dipole moments are directed along the $\mathrm{C}_{2}$ axes, i.e., through the centre of the perylene core along the short perylene axis for compounds 3,7 and 9, normal to the molecular (average) plane for compounds $\mathbf{2}, \mathbf{4}$ and $\mathbf{8}$. The dipole moments are almost null for the almost centrosymmetric compounds 2, 4 and 9. On the other hand, the cis cyanobenzene-disubstituted 3 has a dipole momente of 6.38 D, and the anisole-disubstituted 7 and 8 have dipole moments of 5.54 and $3.89 \mathrm{D}$ in the ground state. For the latter two, the negative ends lie on the side of the methoxy groups.

\subsubsection{Electronic spectra}

The above ground-state geometries were used for a test TD-DFT study on compounds $\mathbf{2 , 3}, \mathbf{4}, \mathbf{7}$ and 8. The most relevant molecular orbitals (MOs) of derivatives 2, $\mathbf{4}$ and $\mathbf{8}$ are depicted in Figure 7. For compound $\mathbf{8}$, except for the extra orbitals localized on the 2,6-diisopropylphenyl substituents orthogonal to the perylene chromophore, the spectroscopically relevant orbitals have a clear oneto-one correspondence with those of PerT obtained at the HMO level.

As a result of the orthogonal configuration of the cyanobenzene substituents relative to the perylene core, the MOs of compound $\mathbf{4}$ are either localized on the latter or on the substituents $(\mathrm{L}+3$ and $\mathrm{L}+4)$. On the other hand, several MOs of compound 8, including the HOMO, feature contributions from both atoms of the perylene core and of the anisole substituents. Some of the MOs are localized on the terminal 2,6-diisopropylphenyl substituents, H-2 and H-3 of all three compounds and H-1, H-4 of compounds $\mathbf{2}$ and $\mathbf{4}$, others on the perylene core, H, L, L+1 and L+2 of compounds $\mathbf{2}$ and $\mathbf{4}$, $\mathrm{L}, \mathrm{L}+1$ and $\mathrm{L}+2$ of compound $\mathbf{8}$. These MO (de)localizations give rise to excited configurations with charge-transfer character, either along the long perylene core axis ( $x$ in Figure 4 ) or between the bay substituents and the perylene core. Orbitals $\mathrm{H}-1$ and $\mathrm{H}-2$ and $\mathrm{H}-3$ and $\mathrm{H}-4$ of compounds 2 
and 4 occur as 'degenerate' pairs given by the - and + combinations of orbitals localized on the two 2,6-diisopropylphenyl substituents. They will give rise to full charge transfer transitions to the perylene-localized L orbital generally characterized by vanishing oscillator strengths. Only one of these two pairs (H-2 and H-3) appears among the five highest occupied MOs in compound 8.

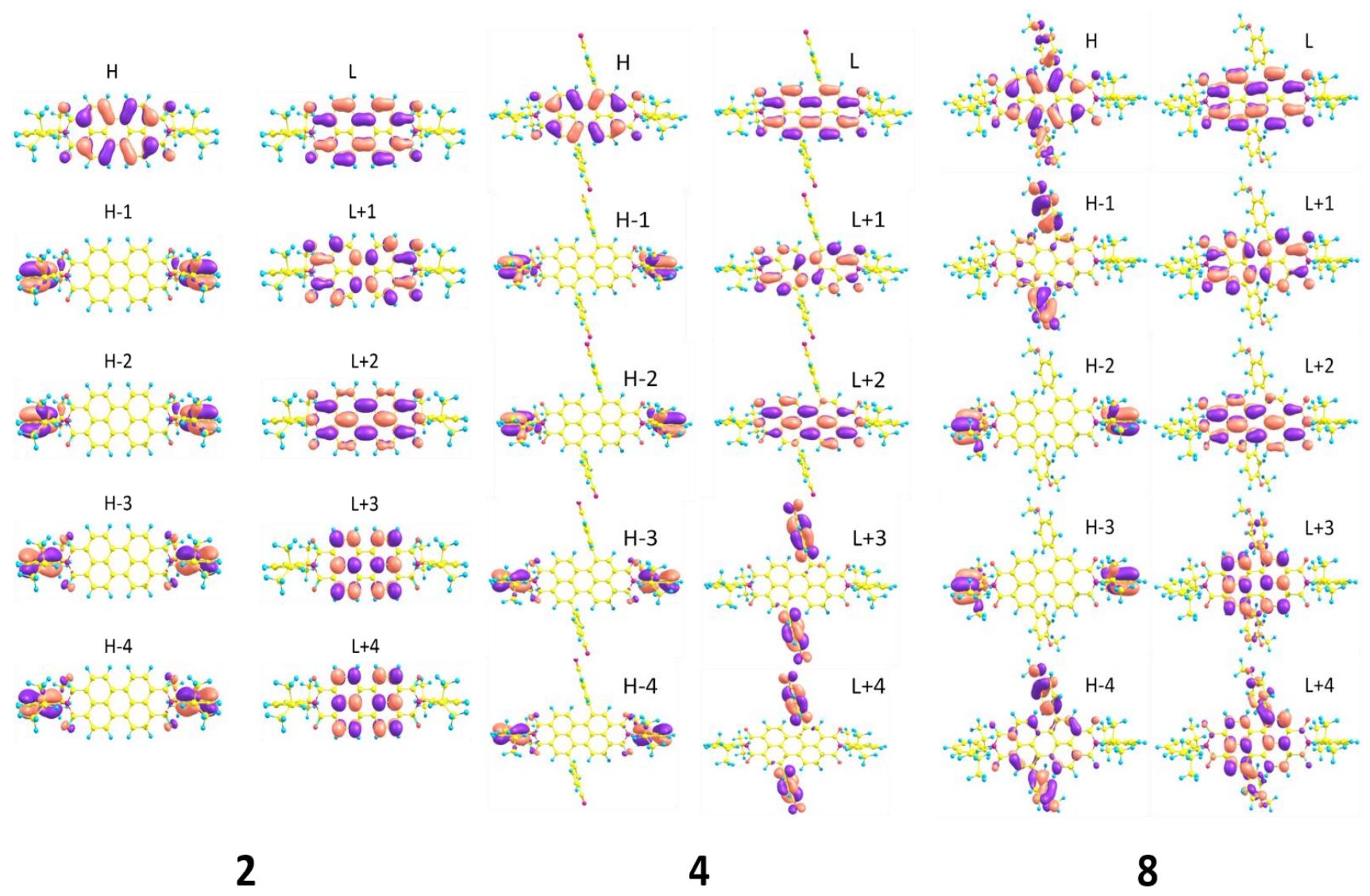

Figure 7. KS DFT molecular orbital pictorial representation for compounds $\mathbf{2 , 4}$ and $\mathbf{8}$ in the gas phase.

No orbitals localized on the bay substituents appear within the spectroscopically relevant MOs for compound 4. On the other hand, owing to the markedly different molecular geometry, these substituent orbitals are more or less delocalized over the central chromophore for compound $\mathbf{8}(\mathrm{H}$, $\mathrm{H}-1, \mathrm{H}-4, \mathrm{~L}+3, \mathrm{~L}+4)$. As a result, such orbitals are pushed near the HOMO and the LUMO orbitals and significant spectral modifications are expected just above the HL transition. 
The MOs of the cis dianisole derivative, 7 (Figure SI2 in the electronic supplementary information), show a remarkable similarity with the orbitals of the corresponding trans derivative, $\mathbf{8}$, in terms of localization on the three subunits, i.e., the perylene core, the bay substituents and the terminal 2,6diisopropylphenyl substituents. As for the cis dicyanobenzene derivative, 3, its H, H-1, H-2, H-3, H-4, L and L+1 MOs show the same localizations exhibited by the corresponding MOs of the trans derivative, 4 (compare Figure 7 with Figure SI3 in the electronic supplementary information), with, however, a significant additional contribution from the bay substituents to the HOMO. Significant differences also appear in the higher MOs, with the L+2 MO mainly localized on the two bay substituents, and the L+3 and L+4 MOs quite delocalized on the perylene core and the cyanobenzenes.

The TD-DFT spectra of compounds $2,3,4,7$ and $\mathbf{8}$, calculated in cyclohexane, are summarized in Table 2. A more extensive presentation of the results obtained in cyclohexane and acetonitrile is provided in Tables SI1-10 of the electronic supplementary information.

The calculated spectrum of reference compound $\mathbf{2}$ in cyclohexane features a single intense HL transition at $522 \mathrm{~nm}$, consistent with the position of the measured lowest-energy strong vibronic band, and with an oscillator strength, $\mathrm{f}=0.86$, higher than the experimental one, 0.56 . Just above the HL transition, the calculated spectrum includes a series of N-2,6-diisopropylphenyl substituentto-perylene core charge-transfer transitions extending to about $370 \mathrm{~nm}$. As predicted by the above orbital analysis, these transitions occur in the form of almost degenerate pairs (corresponding to the pairs of N-2,6-diisopropylphenyl substituent orbitals) and are essentially forbidden. Thus, the TD-DFT calculation provides a qualitatively convincing explanation for the absence of appreciable absorptions beyond the first intense band in the spectrum of compound 2 (Figure 3). The spectrum in acetonitrile (Table SI2) is unmodified with respect to the spectrum in cyclohexane, apart from a general hypsocromic shift (about $30 \mathrm{~nm}$ ) of the N-2,6-diisopropylphenyl substituents-to-perylene CT transitions, a finding consistent with the decrease in charge separation along the long molecular axis brought about by these transitions.

As expected from the close similarity of the five highest occupied and three lowest unoccupied MOs of compounds 2 and 4 (Figure 7), the calculated low- and medium-energy spectrum of compound 4 is almost a replica of that of compound 2 (see Tables 2 and SI1-4). For compound 4 in cyclohexane, we find a perylene-centered HL transition at $520 \mathrm{~nm}$ with an oscillator strength of 0.77 , followed by a series of weak/forbidden pairs of N-2,6-diisopropylphenyl-to-perylene CT transitions fully equivalent to those of compound $\mathbf{2}$. None of the low-/medium-energy transitions involves MOs centered on the cyanobenzene substituents (e.g, L+3 and L+4). On the whole, the TD-DFT calculation attributes a marginal spectroscopic role to the cyanobenzene substituents. 
Similarly to the case of reference compound $\mathbf{2}$, the main change found in the spectrum calculated in acetonitrile (Table SI4) is a marked blue-shift (30-35 $\mathrm{nm}$ ) of all the charge-transfer transitions.

Table 2. TD-DFT absorption spectra of compounds 2,4 and 8 in cyclohexane.

\begin{tabular}{|c|c|c|c|c|}
\hline & $\lambda / \mathrm{nm}$ & $\mathrm{f}$ & Composition* & $\lambda^{\exp / n m}\left(\varepsilon / \mathrm{M}^{-1} \mathrm{~cm}^{-1}\right)$ \\
\hline \multirow{4}{*}{2} & 520 & 0.864 & $0.988[\mathrm{HL}]$ & $517(86000)$ \\
\hline & 487 & 0 & & \\
\hline & 486 & 0.019 & $0.980[(\mathrm{H}-2) \mathrm{L}]$ & \\
\hline & $452,451,381,381,372,357,354$ & 0 & & $363(3000)$ \\
\hline \multirow{5}{*}{3} & 580 & 0.484 & $0.989[\mathrm{HL}]$ & $547(16000)$ \\
\hline & $517,516,474$ & 0 & & \\
\hline & 431 & 0.113 & $0.946[(\mathrm{H}-5) \mathrm{L}]$ & $415(4000)$ \\
\hline & 414 & 0.117 & $0.940[(\mathrm{H}-6) \mathrm{L}]$ & \\
\hline & $389,388,377,376$ & 0 & & \\
\hline \multirow{4}{*}{4} & 520 & 0.773 & $0.972[\mathrm{HL}]$ & $533(31000)$ \\
\hline & 496 & 0 & & \\
\hline & 494 & 0.036 & $0.964[(\mathrm{H}-2) \mathrm{L}]$ & \\
\hline & $457,457,388,385,381,375,371,358$ & 0 & & \\
\hline \multirow{5}{*}{7} & 642 & 0.309 & $0.979[\mathrm{HL}]$ & $575(15000)$ \\
\hline & 564 & 0.129 & $0.990[(\mathrm{H}-1) \mathrm{L}]$ & $470(9000)$ \\
\hline & 471,472 & 0 & & \\
\hline & 454 & 0.307 & $0.961[(\mathrm{H}-4) \mathrm{L}]$ & $435(10000)$ \\
\hline & $439,439,402,392,388,377,375,374$ & 0 & & \\
\hline \multirow{6}{*}{8} & 620 & 0.358 & $0.941[\mathrm{HL}]$ & $557(24000)$ \\
\hline & 540 & 0 & & \\
\hline & 472 & 0.105 & $0.885[(\mathrm{H}-2) \mathrm{L}] ; 0.096[(\mathrm{H}-4) \mathrm{L}]$ & $450(5000)$ \\
\hline & 470 & 0 & & \\
\hline & 462 & 0.322 & $0.874[(\mathrm{H}-4) \mathrm{L}] ; 0.083[(\mathrm{H}-2) \mathrm{L}]$ & $410(10000)$ \\
\hline & $439,439,384,380,377,376,376,371$ & 0 & & \\
\hline
\end{tabular}

* Squared coefficients 
Compared with the spectrum of compound 4, the partial delocalization of the HOMO of the cis derivative $\mathbf{3}$ on the cyanobenzene substituents, related with the less twisted geometry of the latter, is reflected in a bathochromic shift and a decrease in the intensity of the HL transition that acquires a partial cyanobenzene-to-core charge-transfer character (see Figure SI3). Its transition energy is somewhat underestimated by the TD-DFT calculation $(580 \mathrm{~nm})$ with respect to the experimental datum (maximum at $547 \mathrm{~nm}$ ). At higher energies, oscillator strength is calculated at 414 and 431 $\mathrm{nm}$, consistently with the weak, but clearly observable broad absorption band system between 360 and $450 \mathrm{~nm}$ (Figure 3).

As found with compounds 2 and 4, the first transitions of the spectra calculated for the cis and trans di-anisole PDI, 7 and 8, in cyclohexane (Tables 2, SI7 and SI9) are well represented by the HL excitation. In these cases, however, the HL transitions are characterized by a relevant anisole-toperylene charge transfer character, and were calculated quite to the red of the measured band maxima, respectively, 642 and $620 \mathrm{~nm}$ vs 575 and $557 \mathrm{~nm}$, thus indicating an overestimated conjugative interaction between the anisole substituents and the distorted perylene core.

An even more marked underestimate of the transition energy was obtained for the second, mediumintensity transition of the cis derivative, 7, calculated at $564 \mathrm{~nm}$ and measured around $470 \mathrm{~nm}$. This excited state is an almost pure (H-1)L excited configuration that corresponds to an almost full charge transfer from the cyanobenze substituents to the perylene core (see Figure SI3 and Table SI7). A better description was obtained with the third intense transition calculated at $454 \mathrm{~nm}$ and measured at $435 \mathrm{~nm}$. This is a (H-4)L excited configuration and has a much lower charge-transfer character.

For the trans derivative 8, following the (HL) transition, the TD-DFT calculation finds two quite intense additional transitions at 472 and $462 \mathrm{~nm}$ that have their experimental counterparts in a broad system of overlapping bands with medium-to-low intensities between 350 and $470 \mathrm{~nm}$ (Figure 3 and Table 2). The excited states reached in these transitions are describable in terms of combination of the $(\mathrm{H}-2) \mathrm{L}$ and $(\mathrm{H}-4) \mathrm{L}$ excited configurations corresponding, respectively, to a full charge transfer from the N-2,6-diisopropylphenyl substituents and from the two anisole substituents to the perylene core. The reduced symmetry in this compound and the proximity of the involved H-2 and H-4 MOs lead to a significant mixing of the two excited configurations thus giving rise to the two allowed excited states.

When the calculation of the spectrum of compound $\mathbf{8}$ is carried out in acetonitrile (Table SI6), the pattern of excited configuration mixing changes. As found in the two cases discussed above, the (H-2)L configuration is probably markedly stabilized with respect to the other nearby configurations and, as a result, it now mixes with the HL configuration rather than with the higher- 
lying $(\mathrm{H}-4) \mathrm{L}$ configuration. Of the transitions to the two resulting excited states, the lowest-lying one, calculated at $637 \mathrm{~nm}$, has a prevalent HL character and an oscillator strength of 0.33 . The transition to the other excited state, with prevalent $(\mathrm{H}-2) \mathrm{L}$ character, is calculated at $473 \mathrm{~nm}$ and has an even larger oscillator strength of 0.45 .

The role of the (H-2)L excited configuration and the effect of symmetry reduction in enabling this to mix with the (H-4)L and HL configurations respectively in cyclohexane and acetonitrile are therefore critical in producing the observed inconsistency between the measured and the calculated spectra of compound $\mathbf{8}$ in the visible region. For the TD-DFT calculation in cyclohexane the main reason of the observed inconsistencies seems to be a too low relative energy of the $(\mathrm{H}-4) \mathrm{L}$ configuration, imputable to overestimation of the conjugative interactions. On the other hand, for the calculation in acetonitrile the inconsistency is related to a too low relative energy of the $(\mathrm{H}-2) \mathrm{L}$ configuration characterized by full charge transfer from the N-2,6-diisopropylphenyl substituents to the perylene core. A similar underestimation was found for the energies of the HL and (H-1)L configurations that share a pronounced charge transfer character from the anisole substituents to the perylene core.

Thus, in the calculations concerning derivatives $\mathbf{3}, \mathbf{7}$ and, more evidently, $\mathbf{8}$, we have observed a systematic underestimate of the energies of excited configurations with significant-to-large chargetransfer character. This is not unexpected, because, as previously emphasized, ${ }^{60,61}$ the standard TDDFT approach fails to provide reliable spectral predictions when configurations with strong chargetransfer character are concerned.

Four and five more transitions with oscillator strengths higher than 0.02 are calculated at wavelengths larger than $300 \mathrm{~nm}$ for compounds $\mathbf{7}$ and $\mathbf{8}$, respectively. Thus, if we focus on the density of transitions with appreciable intensities in the visible-near UV spectral region, the TDDFT results confirm the HMO analysis concerning the spectroscopic consequences of symmetry reduction in compounds 7 and 8 (Per-C and Per-T) with respect to compounds 2 and 4, both assimilable to perylene.

\subsection{Fluorescence and photophysics}

While the rigid reference compound 2 exhibits a very small Stokes shift, $150 \mathrm{~cm}^{-1}$ in cyclohexane, 360 and $490 \mathrm{~cm}^{-1}$ in acetonitrile and methanol (see Table 1), all bay-substituted PDI feature much larger Stokes shifts. These are between ca 1400 and $2400 \mathrm{~cm}^{-1}$ in cyclohexane and are mainly due to larger emission bathochromic shifts, indicative of a structural relaxation involving the substituents in the lowest excited state (see also the corrected emission spectra of several selected compounds in cyclohexane and acetonitrile in Figure SI4 of the electronic supplementary 
information). In keeping with the observation of stronger spectroscopic effects of anisole $v s$ cyanobenzene bay substitution, anisole-disubstituted PDI in cyclohexane feature somewhat larger Stokes shifts than cyanobenzene derivatives, the latter showing again hardly any difference between meta and para substitution. While the emission solvatochromism of the cyano-benzene substituted PDI $\mathbf{3}$ and $\mathbf{4}$ is almost as weak as that of the reference unsubstituted compound, 2, an emission shift of $1000-1400 \mathrm{~cm}^{-1}$ is observed for anisole-substituted compounds on moving from the low-polarity to the polar solvents. Overall, cis-disubstituted PDI exhibit slightly larger Stokes shifts thus, presumably, larger conformational relaxation in the $S_{1}$ state, than trans-disubstituted derivatives. Among the three anisole-substituted PDI, the lowest Stokes shift is exhibited by the tetrasubstituted compound $\mathbf{9}$, likely due to a somewhat hindered structural relaxation imposed by steric crowding at the bay regions.

Radiative rate constants nicely parallel the oscillator strengths of the lowest-energy absorption bands and are almost independent of the solvent for reference compound $\mathbf{2}$ and cyanobenzene derivatives, whenever checked. The same occurs with the corresponding radiationless-decay rate constants, $\mathrm{k}_{\mathrm{nr}}$. These are 2-3 times larger for the four cyanobenzene derivatives than for reference compound, 2, a finding that indicates that this substitution, besides having little spectroscopic consequences, also fails to open new efficient radiationless decay paths.

Anisole disubstitution, on the other hand, combined with a high solvent polarity, completely changes the photophysical behaviour with respect to the other PDI. The radiative rate constants of the anisole-disubstituted compounds significantly decrease, $6 v s 3,11 v s 4\left(10^{7} \mathrm{~s}^{-1}\right)$ for $\mathbf{7}$ and $\mathbf{8}$, respectively, moving from cyclohexane to the polar solvents, with a further small decrease in protic methanol relative to aprotic acetonitrile. The decrease in the radiative rate constants goes parallel with the increase in the Stokes shifts/emission red-shifts. Combined, these results suggest that solute/solvent electrostatic interactions trigger an $\mathrm{S}_{1}$-state relaxation to dipolar conformations whose radiative vertical transitions to the ground-state have a significantly higher CT character than the strongly emitting conformations reached in cyclohexane. The observation of a smaller decrease in the radiative rate constant and of smaller emission red-shifts/ Stokes shift increases for the crowded, tetrasubstituted derivative 9 suggests this excited-state relaxation to involve twisting of the bay-substituent phenyl rings.

The biggest observed effect of solvent polarity concerned the non-radiative decay rates of anisolesubstituted PDI. As a consequence of cyanobenzene bay disubstitution, these rate constants increase by a factor only around 3 and are solvent independent, with slightly larger values found for cis substitution. On the other hand, the two di-anisole derivatives feature an order-of-magnitude increase of the radiationless decay rate constants in acetonitrile relative to cyclohexane, and an 
additional 4-5-time increase on moving to methanol. In an attempt to identify this new fast radiationless decay route, we tested whether it could correspond to a solvent-polarity activated intersystem crossing to the triplet manifold. Perylene, like other condensed aromatic hydrocarbons, features a singlet-to-triplet intersystem crossing rate constant only about $2 \times 10^{6} \mathrm{~s}^{-1}$. ${ }^{62}$ While most investigated PDI did not show triplet-triplet absorption upon direct photoexcitation, a tetra- and an octa-chlorinated PDI did show such an absorption. ${ }^{63}$ These triplet-triplet spectra, as well as those of a number of PDI obtained by triplet-triplet sensitization or heavy-atom effect, featured broad bands with maxima around $500 \mathrm{~nm}$. ${ }^{63-65}$ We performed explorative laser flash photolysis experiments on compound $\mathbf{8}$ in acetonitrile, but failed to observe T-T absorption in the $450-550 \mathrm{~nm}$ region. Using the thiacarbocyanine iodide photoisomer as a reference transient absorber, ${ }^{42}$ we could establish an upper limit for the product of the singlet-to-triplet intersystem crossing quantum yield and the change in molar extinction coefficient at $500 \mathrm{~nm}$ between the ground $(\mathrm{S})$ and the lowest triplet (T) states, $\operatorname{\Phi isc}\left(\varepsilon_{\mathrm{T}-} \varepsilon_{\mathrm{S}}\right)<|1500| \mathrm{M}^{-1} \mathrm{~cm}^{-1}$. Using $\Delta \varepsilon_{\mathrm{TS}} \sim 30000 \mathrm{M}^{-1} \mathrm{~cm}^{-1}$, ${ }^{63,64}$ we estimate $\Phi$ isc $<0.05$ for compound $\mathbf{8}$ in acetonitrile and, for the corresponding rate constant, $\mathrm{k}_{\mathrm{isc}}<$ $2 \times 10^{7} \mathrm{~s}^{-1}$, an upper value inconsistent with the measured $\mathrm{k}_{\mathrm{nr}}$.

\section{Discussion}

We can analyze the optical properties of the PDI studied here in terms of their more or less marked reminiscence of their common centrosymmetric perylene parent system. As a general consequence of (quasi) central symmetry, one would expect weak/vanishing dipole moments, thus a weak dependence of the absorption spectrum on the solvent polarity, and large quadrupole moments. Moreover, formal central symmetry implies a negligible first hyperpolarizability, $\boldsymbol{\beta}$ and a twophoton forbidden transition to the first $(g \rightarrow u)$ excited state responsible for the intense long wavelength absorption band in the one photon (OP) spectrum. On the contrary, a two-photon allowed transition is expected to occur between the ground state and the 'second' $(g \rightarrow g)$, OP forbidden, excited state. Based on the close similarity of the 2PA spectra of centrosymmetric reference compound $\mathbf{2}$ and of cis and trans bay disubstituted cyanobenzene derivatives (compounds 3-6), we conclude that, as a result of weak or negligible conjugative interactions, the centrosymmetrical nature of the perylene core represents the most relevant feature of these derivatives when their nonlinear optical properties are concerned.

This remains only qualititavely true for the anisole derivatives, compounds 7-9, because conjugative interactions cause significant modifications of their OP and 2PA spectra. Anisole bay substitution deeply changes the perylene-core electronic distribution with respect to cyanobenzene bay substitution, thence the equilibrium geometries and the related observables. Difference are 
particularly evident between the two trans derivatives, $\mathbf{4}$ and $\mathbf{8}$. The equilibrium twist angles of the substituent phenyl rings with respect to the perylene core are very different in the two compounds, 90 vs $59^{\circ}$, and goes together with a significant difference in the perylene-core geometry, planar vs distorted by $17^{\circ}$. A torsion of the perylene core similar to those found with compounds $\mathbf{7 , 8}$ and $\mathbf{9}$ was observed with tetra-aryloxy PDI and was attributed to repulsive interactions between the four connecting oxygen atoms. ${ }^{50,54}$ Such repulsions between atoms of different substituents in the same bay are certainly important in our cis disubstituted derivatives and are actually critical in determining the substituent-ring arrangement and the peculiar core distorion that compounds $\mathbf{3}$ and 7 share in spite of the different electronic nature of their substituents. However, they do not exist in compounds $\mathbf{4}$ and $\mathbf{8}$, where they are possibly replaced by much looser repulsions between hydrogen atoms at the unsubstituted bay positions and at the ortho positions of the substituent phenyl rings. Yet, while these repulsions should be very similar in the two trans PDI, the resulting DFT core geometries differ markedly, a finding that must be related with electronic differences between the two substituents.

We propose that in bay-substituted PDI the twist angles of the substituents relative to the perylene core as well the distortion of the latter out of planarity result from a compromise between two opposite driving forces, i.e., steric repulsion in the crowded bay areas, leading to a perpendicular substituent arrangement and a planar core, and susbtituent-core electronic conjugation, favoring core/substituent coplanarity. Because of the strong electron-accepting nature of the carboxydiimide substituents of the PDI core, ${ }^{66}$ and the electron withdrawing nature of the $\mathrm{CN}$ group of the cyanobenzene substituents, no significant driving force for electron flow between the core and the bay substituents exists in cyanobenzene-susbtituted PDI. Thus, in the absence of bay-substituent crowding, i.e., for trans derivatives $\mathbf{4}$ and $\mathbf{6}$, the systems relax to geometries characterized by planar cores and perpendicular cyanobenzene substituents.

When cyanobenzene is replaced by electron-donating anisole, a driving force for a substituent-tocore electron flow sets in. As a consequence, twisting of the anisole substituents and perylene core distortion out of planarity result from a compromise between steric repulsion and conjugation tendency. Using a hydraulic analogy, we may say that this partial twisting of the anisole substituents corresponds to a partial opening of a butterfly valve for electron flow from the substituents to the perylene core.

However, substitution topology, i.e., cis vs trans anisole disubstitution, causes significant differences between the resulting geometries. The trans arrangement of the substituents, therefore of the electron-flow driving forces, induces a chiral distortion of the perylene core reminiscent of a propeller. On the other hand, the $c$ is arrangement of compound 7 determines a different, achiral 
distortion of the perylene core that is much the same as in cis cyanobenzene-disubstituted compounds. Therefore, in our cis-substituted PDI, steric repulsion alone determines the conformational preferences. This said, we must add that the perylene core distortion in compounds 3 and 7-9 does not seem to produce spectacular consequences on the spectroscopic observables. Its directly observable effects probably consist in the more pronounced vibronic-structure blurring 54 of the lowest-energy electronic bands of these derivatives relative to undistorted compound $\mathbf{4}$, even though different torsional mobilities of the substituent phenyl rings might also contribute to this phenomenon. 52,53

The close similarity of the geometries of the two cis-disubstituted compounds, $\mathbf{3}$ and $\mathbf{7}$, offers an opportunity to understand the effects of the different electronic nature of the substituents separately from those of the perylene core distortion on the positions and intensities of the absorption/emission bands, as well as on the photophysics of these two derivatives. Concerning the spectral observables, these effects are limited to moderate red shifts of the OP absorption $\left(-900 \mathrm{~cm}^{-1}\right)$ and the emission maxima (-1600 $\mathrm{cm}^{-1}$, both in cyclohexane) with a slight decrease in intensity, and a moderate increase in the 2PA intensity in the investigated spectral range. However, they become decisive in determining completely different photophysical behaviours in polar solvents, where the cyanobenzene derivative remains highly emissive while the anisole derivative is almost completely quenched.

The very small solvent-polarity dependence of the lowest-energy absorption bands of all investigated PDI implies small dipole-moment changes upon excitation to the lowest excited state. On the other hand, polar solvents cause strong effects on the fluorescence/photophysical properties of the three anisole-substituted PDI. The ca. $2000 \mathrm{~cm}^{-1}$ Stokes shifts observed for all PDI in cyclohexane indicate the occurrence of excited-state relaxations that lead to conformations still characterized by high radiative decay probabilities. However, only the three anisole-substituted PDI feature, together with an additional $1000 \mathrm{~cm}^{-1}$ Stokes-shift, a marked increase in the radiationless decay rate constant in polar solvents. Emission quenching in polar solvents has been previously observed with PDI substituted at the two nodal $\mathrm{N}$ atoms by mono-, di- and trimethoxy benzenes, ${ }^{29}$ with PDI trans-disubstituted with triphenylammino and carbazolyl goups ${ }^{59}$ and tetrasubstituted at the bay positions either with bridged phenoxy substituents forced to adopt a perpendicular arrangement relative to the perylene core, ${ }^{28}$ or with four para and meta methoxy substituted aryloxy substituents, ${ }^{30}$ and with PDI made asymmetrical by single substitution at a bay position with electron releasing alkynyl-phenyl substituents. ${ }^{31}$ In all these contributions, efficient photo-induced intramolecular electron transfer, demonstrated by a photoelectrical characterization in the case of carbazolyl-substituted PDI, ${ }^{59}$ has been associated with the fluorescence quenching. 
In particular, in ref. 24, an alkynyl-p-dimethylaminophenyl substituent caused a full quenching of the emission of the parent PDI even in toluene. Freezing of the substituent twisting/solvent reorganization caused by a solvent viscosity increase and temperature decrease, resulted in recovery of the quenched emission. Based on this observation and on ultrafast excited-state absorption and emission characterization, the fast radiationless decay was attributed to conversion to twisted intramolecular (substituent)HOMO $\rightarrow$ (PDI core)LUMO charge transfer configurations, stabilized by solute-solvent electrostatic interactions to create $\mathrm{S}_{1}$-state minima (if not already such in apolar solvents). From these twisted configurations, fast back electron-transfer radiationless decays strongly competitive with radiative decays were proposed to occur.

A similar phenomenon might occur with our dianisole PDI $\mathbf{7}$ and $\mathbf{8}$ and, to a smaller extent, the tetrasubstituted derivative 9 in polar solvents. Because of the electron-donating character of the $p$ anisole substituents, following torsion of the phenyl rings towards more twisted geometries compatible with the different steric hindrances active in the three compounds, more chargeseparated conformations, characterized by lower radiative rate constants and fast radiationless decays, might be obtained in the $\mathrm{S}_{1}$ state. Such CT conformations must be stabilized by electrostatic interactions with and a polar solvent. As anticipated in the introduction, however, invoking a decisive role for these interactions in compounds such as the trans anisole-disubstituted $\mathbf{8}$ and the tetrasubstituted 9 raises doubts connected with the almost centrosymmetric nature of these systems and the corresponding small electric dipole moments in the ground state. Similar spectroscopic observations, i.e., negligible absorption and marked emission solvatochromic shifts, were observed with other highly symmetric, quadrupolar compounds. ${ }^{58}$ They were interpreted in terms of symmetry breakage associated with coupling of the electrons with nuclear vibrations and a slow orientational motion of a polar solvent. As a result, for proper molecules in polar solvents, i.e., systems in which the vibrational plus solvation relaxation energy is higher than a threshold value, the symmetry is broken and the excited-state potential-energy surface features two minima corresponding to two dipolar conformations. ${ }^{67} \mathrm{~A}$ similar, yet uncharacterized symmetry breakage might take place in our anisole-substituted PDI in polar solvents.

Worth mentioning, many of the examples from the literature on PDI with quenched emission in polar solvents are compounds with planar perylene cores and, on the contrary, derivative $\mathbf{3}$, with its distorted core, does not show this feature. Thus, core distortion such as found with compounds 7-9 is neither a prerequisite nor an impediment for this process to occur: it can, instead, be seen as an additional structural relaxation opportunity in the compromise between oppositely acting electronic, electrostatic and steric forces. 


\section{Conclusions}

The present work has highlighted several basic characteristics of recently synthesized bay di- and tetra-substituted PDI 3-9 related with their peculiar electronic structures. The electronic nature of the bay substituents and the steric hindrance in the substituted bay areas have proved decisive in determining the equilibrium geometries, the spectra and the photophysics of PDI 3 to 9. trans disubstitution with electron-withdrawing cyanobenzenes, with their phenyl rings normal to the perylene plane, only introduced essentially inductive interactions with the core. The large spectral range with negligible absorption above the lowest-energy intense band of this derivative is consistent with localization of all the MOs in either the perylene core or in the N-2,6diisopropylphenyl end substituents or in the cyanobenzene bay substituents, and the resulting large number of forbidden CT transitions in that spectral range.

Steric repulsion between the cyanobenzene groups in the cis derivative causes a distortion of the perylene core and an arrangement of the substituent rings with a markedly decreased twist angle. This goes together with a significant delocalization of the HOMO on the substituents and the appearance of some charge-transfer character in the HL intense transition. The significant symmetry reduction is consistent with the observation of some oscillator strength between the intense visible and the UV bands. The weakness of the electronic effects of the cyanobenzene substituents is further shown by the similarity of the 2PA spectra of all derivatives, including the para- and meta-disubstituted, as well as of their fluorescence properties, that show only small red shifts and quantum yield decreases on moving from cyclohexane to polar solvents.

Electron-donating anisole substituents, on the other hand, proved able to give rise to pronounced changes in some of in the investigated properties. In such derivatives, the driving force for substituent-to-core electron flow is much larger than with the cyanobenzene-substituted PDI. However, in the cis derivative the need to relieve steric hindrance still dominates the conformational preference that is very similar to that of the corresponding cyanobenzene derivative. A similar, if not worse hindrance likely determines the geometry of the tetrasubstituted derivative. It is thus only with the trans derivative, compound $\mathbf{8}$, that a compromise between the two forces is fully operative and generates an equilibrium geometry with substituent phenyl rings twisted by $59^{\circ}$ and a peculiar, chiral distortion of the perylene core.

For all anisole substituted PDI, conjugative interactions between the substituents and the central chromophore cause spectral red-shifts and a change in the shape and intensities of both the oneand the two-photon absorption spectra. These are explained in terms of symmetry reduction and of 
a delocalization of some of the spectroscopically relevant MOs, with the appearance of intermediate-energy transitions that, while preserving CT character, exhibit significant oscillator strengths. Most affected by the anisole bay substitution are the fluorescence properties. The large Stokes shifts and the emission quenching of anisole disubstituted derivatives in polar solvents indicate the occurrence of a solvent-polarity driven relaxation in the excited-state to a more chargeseparated conformation, characterized by lower radiative and much faster radiationless decay rates. Given the symmetry of the anisole-substituted PDI, this phenomenon might be triggered by a symmetry breakage associated with electronic coupling with nuclear vibrations and orientational motion of a polar solvent. The nuclear coordinate likely involves twisting of the anisole phenyl rings and is somewhat restrained for the tetrasubstituted compound, possibly because of increased hindrance in the bay areas.

A secondary role in determining the measured properties of our disubstituted PDI is played by the substitution topology. Cis derivatives exhibit systematically red-shifted one-photon absorption and emission spectra, a fact that assimilate PDI to substituted polyenes, but might be simply related with the lower twisting of the bay substituents. As for the fluorescence and photophysical properties, these are qualitatively conserved within cis/trans pairs of compounds, 3/4, 5/6 and, in spite of a significantly different perylene-core distortion, $\mathbf{7 / 8}$.

Compared with the extensively studied phenoxy-substituted PDI, direct attachment of the aromatic rings at the bay positions has led, in the case of the anisole-substituted compounds, to stronger substituent-core conjugative interactions that have manifested themselves as marked red shifts of both absorption and fluorescence emission.

Overall, these findings, and their theoretical analysis, form a basis of knowledge sufficient to propose our anisole-substituted derivatives as new PDI with enhanced electronic conjugation. Thanks to their strong sensitivity to the polarity of the environment, the optical and, particularly, photophysical properties of these compounds can be modulated within a wide range of responses, both in terms of spectral position and of emission intensity. 


\section{References and footnotes}

1 M. Kardos, Deutsches Reichspatent DE 276357, 1913 (Chem. Abstr., 1914, 8, 22317); M. Kardos Deutsches Reichspatent DE 2769561913 (Chem. Abstr., 1915, 9, 6398).

2 W. Herbst and K. Hunger, Industrial Organic Pigments; Wiley-VCH, Weinheim, 2004; H. Zollinger, Color Chemistry, Verlag Helvetica Chimica Acta, Zürich, 2003.

3 H. Langhals, Heterocycles, 1995, 40, 477.

4 T. Weil, T. Vosch, J. Hofkens, K. Peneva and K. Müllen, Angew. Chem. Int. Ed., 2010, 49, 9068.

5 L. Cheng and K. Müllen, J. Mater. Chem. C, 2014, 2, 1938-1956.

6 F. Würthner, C. R. Saha-Möller, B. Fimmel, S. Ogi, P. Leowanawat and D. Schmidt, Chem. Rev., DOI: $10.1021 /$ acs.chemrev.5b00188

7 M. Barra, F. V. Di Girolamo, F. Chiarella, M. Salluzzo, Z. Chen, A. Facchetti, L. Anderson and A. Cassinese, J. Phys. Chem. C, 2010, 114, 20387; W. Jiang, Y. Li and Z. Wang, Acc. Chem. Res., 2014, 47, 3135.

8 C. Huang, S. Barlow and S. R. Marder, J. Org. Chem., 2011, 76, 2386.

9 C. R. Newman, C. D. Frisbie, D. A. da Silva Filho, J.-L. Brédas, P. C. Ewbank and K. R. Mann, Chem. Mater., 2004, 16, 4436; Y. Sun, Y. Liu and D. Zhu, J. Mater. Chem., 2005, 15, 53; T. U. Kampen, Low Weight Organic Semiconductors, Wiley-VCH, Weinheim, 2010; H. Usta, A. Facchetti and T. J. Marks, Acc. Chem. Res., 2011, 44, 501; X. Zhan, A. Facchetti, S. Barlow, T. J. Marks, M. A. Ratner, M. R. Wasielewski and S. R. Marder, Adv. Mater., 2011, 23, 268; J. Mei, Y. Diao, A. L. Appleton, L. Fang and Z. Bao, J. Am. Chem. Soc., 2013, 135, 6724; Z. Liu, G. Zhang, Z. Cai, X. Chen, H. Luo, Li, Y.J. Wang and D. Zhang, Adv. Mater., 2014, 26, 6965.

10 K.-Y. Law, Chem. Rev., 1993, 93, 449; Z. Y. Wang, Y. Qi, J. P. Gao, G; C. Sacripante, P. R. Sundararajan and J. D. Duff, Macromolecules, 1998, 31, 2075.

11 L. Zang, Y. Che and J. S. Moore, Acc. Chem. Res., 2008, 41, 1596; J. R. Siekierzycka, C. Hippius,

F. Würthner, R. M. Williams and A. M. Brouwer, J. Am. Chem. Soc., 2010, 132, 1240; X. Feng, Y. An, Z. Yao, C. Li and G. Shi, ACS Appl. Mater. Interfaces, 2012, 4, 614.

12 Q. Al-Galiby, I. Grace, H. Sadeghi and C.J. Lambert, J. Mater. Chem. C, 2015, 3, 2101.

13 M. Sadrai and G; R. Bird, Optics Commun., 1984, 51, 62; M. G. Ramírez, S. Pla, P. G. Boj, J. M. Villalvilla, J. A. Quintana, M. A. Díaz-García, F. Fernández-Lázaro and Á. Sastre-Santos, Adv. Optical Mater., 2013, 1, 933.

14 K. D. Belfield, M. V. Bondar, F. E. Hernandez and O. V. Przhonska, J. Phys. Chem. C, 2008, 112,5618 
15 Y. Li, T. Liu, H. Liu, M.-Z. Tian and Y. Li, Acc. Chem. Res., 2014, 47, 1186; J. Qu, J. Zhang, A. C. Grimsdale, K. Müllen, F. Jaiser, X. Yang and D. Neher, Macromolecules 2004, 37, 8297; X. Z. Jiang, Y. Q. Liu, S. G. Liu, W. F. Qiu, X. Q. Song and D. B. Zhu, Synth. Met., 1997, 91, 253. 16 Y. Ooyama and Y. Harima, Eur. J. Org. Chem., 2009, 2903; M. Sommer, S. Hüttner and M. Thelakkat, In Ideas in Chemistry and Molecular Sciences, Advances in Nanotechnology, Materials and Devices, (Ed: B. Pignataro), Wiley-VCH: Weinheim, 2010, pp. 317-338; V. Kamm, G. Battagliarin, I. A. Howard, W. Pisula, A. Mavrinskiy, C. Li, K. Müllen and F. Laquai, Adv. Energy Mater., 2011, 1, 137; E. Zhou, J. Cong, Q. Wei, K. Tajima, C. Yang and K. Hashimoto, Angew. Chem Int. Ed., 2011, 50, 2799; C. Li and H. Wonneberger, Adv. Mat., 2012, 24, 613; C. Li, M. Liu, N. G. Pschirer, M. Baumgarten and K. Müllen, Chem. Rev., 2010, 110, 6817; Y. Lin, Y. Li and X. Zhan, Chem. Soc. Rev., 2012, 41, 4245; C. Li and H. Wonneberger, Adv. Mat., 2012, 24, 613; E. Kozma and M. Catellani, Dyes Pigm., 2013, 98, 160; S. D. Dimitrov and J. R. Durrant, Chem. Mater., 2014, 26, 616.

17 Z. Chen, U. Baumeister, C. Tschierske and F. Würthner, Chem. Eur. J., 2007, 13, 450; A. Wicklein, A. Lang, M. Muth and M. Thelakkat, J. Am. Chem. Soc., 2009, 131, 14442; J. Kelber, M.-F. Achard, F. Durola and H. Bock, Angew. Chem. Int. Ed., 2012, 51, 5200.

18 M. Green, In High Performance Pigments (Ed: H. M. Smith), Wiley-VCH, Weinheim, 2002, pp. 249-261; A. M. Dhalla, M. M. Sait, S. N. Naik and P. J. Nadkarni, Chem. Industry Digest, 2008, 21, 72; C. D. Schmidt and A. Hirsch, In Ideas in Chemistry and Molecular Sciences, Advances in Synthetic Chemistry (Ed: B.Pignataro), Wiley-VCH; Weinheim, 2010, pp. 283-304.

19 M. Bendikov, F. Wudl and D. F. Perepichka, Chem. Rev., 2004, 104, 4891; F. C. De Schryver, T. Vosch, M. Cotlet, M. van der Auweraer, K. Müllen and J. Hofkens, Acc. Chem. Res., 2005, 39, 514; K. Peneva, G. Mihov, F. Nolde, S. Rocha, J.-i. Hotta, K. Braeckmans, J. Hofkens, H. Uji-I, A. Herrmann and K. Müllen, Angew. Chem., 2008, 120, 3420; S. Rocha, J. A. Hutchison, K. Peneva, A. Herrmann, K. Mullen, M. Skjot, C. I. Jorgensen, A. Svendsen, F.C. De Schryver, J. Hofkens and H. Uji-i, Chem. Phys. Chem., 2009, 10, 151; D. Wöll, E. Braeken, A. Deres, F. C. De Schryver, H. Uji-i and J. Hofkens, Chem. Soc. Rev., 2009, 38, 313.

20 C. Kohl, T. Weil, J. Qu and K. Müllen, Chem. Eur. J., 2004, 10, 5297.

21 N. Soh and T. Ueda, Talanta, 2011, 85, 1233; Y. Huang, L. Fu, W. Zou and F. Zhang, New J. Chem., 2012, 36, 1080.

22 H. Langhals, Helv. Chim. Acta, 2005, 88, 1309; F. Würthner, Pure Appl. Chem., 2006, 78, 2341; J. Baggerman, D. C. Jagesar, R. A. L. Vallée, J. Hofkens, F. C. De Schryver, F. Schelhase, F. Vögtle and A. M. Brouver, Chem. Eur. J., 2007, 13, 1291; J. Gebers, D. Rolland and H. Frauenrath, Angew. Chem. Int. Ed., 2009, 48, 4480; C. Backes, F. Hauke and A. Hirsch, Adv. 
Mater., 2011, 23, 2588; S. Suzuki, M. Kozaki, K. Nozaki and K. Okada, J. Photochem. Photobiol. C: Photochem. Rev., 2011, 12, 269; D. Görl, X. Zhang and F. Würthner, Angew. Chem. Int. Ed., 2012, 51, 6328; A. N. Basuray, H.-P. J. de Rouville, K J. Hartlieb, A. C. Fahrenbach and J. F. Stoddart, Asian J. Chem., 2013, 8, 524; A. G. Slater, L. M. A. Perdigão, P. H. Beton and N. R. Champness, Acc. Chem. Res., 2014, 47, 3417.

23 J. Mareda and S. Matile, Chem. Eur. J., 2009, 15, 28.

24 E. Micheli, D. D'Ambrosio, M. Franceschin and M. Savino, Mini-Rev. Med. Chem., 2009, 9, 1622; M. Franceschin, Eur. J. Org. Chem., 2009, 2225.

25 M. R. Wasielewski, Acc. Chem. Res., 2009, 42, 1910; G. Hinze, R. Métivier, F. Nolde, K. Müllen and T. Basché, J. Chem. Phys., 2008, 128, 124516; M. Dill, M. C. Baier, S. Mecking and D. Wöll, Angew. Chem. Int. Ed., 2013, 52, 12435.

26 M. Neumann, S. Füldner, B. König and K. Zeitler, Angew. Chem. Int. Ed., 2011, 50, 951; I.

Ghosh, T. Ghosh, J. I. Bardagi and B. König, Science, 2014, 346, 725.

27 F. Würthner, Chem.Commun., 2004, 1564 and refs. therein.

28 P. Osswald and F. Würthner, Chem. Eur. J., 2007, 13, 7395.

29 L. Flamigni, B. Ventura, A. Barbieri, H. Langhals, F. Wetzel, K. Fuchs and A. Walter, Chem. Eur. J. 2010, 16, 13406.

30 E. Fron, G. Schweitzer, P. Osswald, F. Würthner, P. Marsal, D. Beljonne, K. Müllen, F.C. De Schryver and M. Van der Auweraer, Photochem. Photobiol. Sci. 2008, 7, 1509.

31 R. Mishra, J.M. Lim, M. Son, P. Panini, D. Kim and J. Sankar, Chem. Eur. J. 2014, $20,5776$.

32 M. Queste, C. Cadiou, B. Pagoaga, L. Giraudet and N. Hoffmann, New J. Chem. 2010, 34, 2537. 33 B. Pagoaga, L. Giraudet and N. Hoffmann, Eur. J. Org. Chem. 2014, 5178.

34 A.A. Granovsky, Firefly version 7G, www.http://classic.chem.msu.su/gran/firefly/index.html.

35 M. W. Schmidt, K. K. Baldridge, J. A. Boatz, S. T. Elbert, M. S. Gordon, J. H. Jensen, S. Koseki, N. Matsunaga, K. A. Nguyen, S. Su, T. L. Windus, M. Dupuis and J. A. Montgomery J. Comput. Chem., 1993, 14, 1347.

36 S. Miertus, E. Scrocco and J. Tomasi Chem. Phys., 1981, 55, 117.

37 J. Tomasi and M. Persico, Chem.Rev. 1994, 94, 2027.

38 R. Cammi and J. Tomasi, J. Comput. Chem. 1995, 16, 1449.

39 D. Magde, R. Wong and P.G. Seybold, Photochem. Photobiol., 2002, 75, 327.

40 I. Lopez Arbeloa and K.K. Rohatagi-Mukherjee, Chem. Phys. Letters, 1986, 129, 607.

41 S.J. Isak and E.M. Eyring, J. Phys. Chem., 1992, 96, 1738.

42 G. Ponterini and F. Momicchioli, Chem. Phys., 1991, 151, 111; I. Baraldi, A. Carnevali, F. Momicchioli and G. Ponterini, Spectrochim. Acta A, 1993, 49A, 471. 
43 C. Xu and W. W. Webb, J. Opt. Soc. Am. B, 1996, 13, 481-491.

44 M. H. V. Werts, N. Nerambourg, D. Pélégry, Y. Le Grand and M. Blanchard-Desce, Photochem. Photobiol. Sci., 2005, 4, 531-538.

45 C. Sissa, V. Parthasarathy, D. Drouin-Kucma, M. H. V. Werts, M. Blanchard-Desce and F. Terenziani, Phys. Chem. Chem. Phys., 2010, 12, 11715.

46 N. S. Makarov, M. Drobizhev and A. Rebane, Opt. Express, 2008, 16, 4029.

47 Y. Zhen, H. Qian, J. Xiang, J. Qu and Z. Wang, Org. Lett. 2009, 11, 3084; W. Jiang, C. Xiao, L. Hao, Z. Wang, H. Ceymann, C. Lambert, S. Di Mottam and F. Negri, Chem. Eur. J. 2012, 18, 6764

48 W. Qiu, S. Chen, X. Sun, Y. Liu and D. Zhu, Org. Lett. 2006, 8, 867.

49 Y. Tanizaki, T. Yoshinaga and H. Hiratsuka, Spectrochimica Acta., 1978, 34A, 205.

50 D. Ambrosek, H. Marciniak, S. Lochbrunner, J. Tatchen, X.-Q. Li, F. Würthner and O. Kühn, Phys. Chem. Chem. Phys., 2011, 13, 17649.

51 By a simple HMO-based Pariser-Parr type calculation using the Ohno-Klopman formula for the electron-repulsion integrals and the alternant-hydrocarbon semplifications for the core matrix, we found the first $\pi \rightarrow \pi^{*}$ transition of cis butadiene to be $0.44 \mathrm{eV}$ to the red of that of trans butadiene, in good agreement with the experimental value $(\sim 0.4 \mathrm{eV})$. For details, see F. Momicchioli, I. Baraldi and M.C. Bruni, Chem. Phys., 1983, 82, 229, and the references cited therein. We also found that the decrease in the transition energy $\left(E_{V}-E_{N}=E_{\mid H L}\right\rangle-E_{\mid H^{2}}{ }^{2}=I_{L}-I_{H}-2 J_{H-1, H}-J_{H, H}$ $+2 J_{H-1, L}+K_{H-1, H}-K_{H-1, L}+J_{H, L}+K_{H, L}$ ) originates in the two-electron terms. A contribution from the one-electron terms arises on removal of the alternant-hydrocarbon simplifications, but the contribution from the electron-electron interactions remains largely prevalent.

52 H. Suzuki, Bull. Chem. Soc. Japan, 1962, 35, 1715.

53 F. Momicchioli, I. Baraldi and M.C. Bruni, J.C.S. Faraday II 1972, 68, 1556; I. Baraldi, F.Momicchioli and M.C. Bruni, J.C.S. Faraday II 1972, 68, 1571.

54 J. Hofkens, T. Vosch, M. Maus, F. Köhn, M. Cotlet, T. Weil, A. Herrmann, K. Müllen and F.C. De Schryver, Chem Phys Lett., 2001, 333, 255.

55 P. Osswald, D. Leusser, D. Stalke and F. Würthner, Angew. Chem. Int. Ed., 2005, 44, 250.

56 W. L. Peticolas, Ann. Rev. Phys. Chem., 1967, 18, 233.

57 M. G. Vivas, C. Diaz, L. Echevarria, C. R. Mendonca, F. E. Hernández and L. De Boni, J. Phys. Chem. B, 2013, 117, 2742.

58 S. A. El-Daly, A. M. Asiri and K. A. Alamry, J. Luminesc., 2014, 24, 1307.

59 R. R. Reghu, H. K. Bisoyi, J. V. Grazulevicius, P. Anjukandi, V. Gaidelis and V. Jankauskas, J. Mat. Chem., 2011, 21, 7811. 
60 A. Dreuw, M. Head-Gordon, Chem. Rev. 2005, 105, 4009.

61 C. A. Ullrich, Time-Dependent Density-Functional Theory : Concepts and Applications, Ch. 9, Oxford University Press, 2012

62 S.L. Murov, I. Carmichael and G.L. Hug, Handbook of Photochemistry, $2^{\text {nd }}$ ed., Dekker, New York, 1993.

63 M. Sadrai, L. Hadel, R. R. Sawers, S. Husain, K. Krogh-Jespersen, J. D. Westbrook and G. R. Bird, J. Phys. Chem. 1992, 96, 7988.

64 W. E. Ford and P. V. Kamat, J. Phys. Chem. 1987, 91, 6373.

65 A. A. Rachford, S. Goeb and F. N. Castellano, J. Am. Chem. Soc., 2008, 130, 2766.

66 S. K. Lee, Y. Zu, A. Herrmann, Y. Geerts, K. Müllen and A.J. Bard, J. Am. Chem. Soc. 1999, 121, 3513.

67 F. Terenziani, A. Painelli, C. Katan, M. Charlot and M. Blanchard-Desce, J. Am. Chem. Soc. 2006, 128, 15742. 